\title{
Working
}

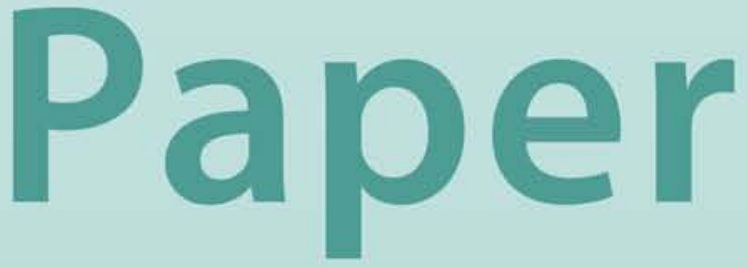




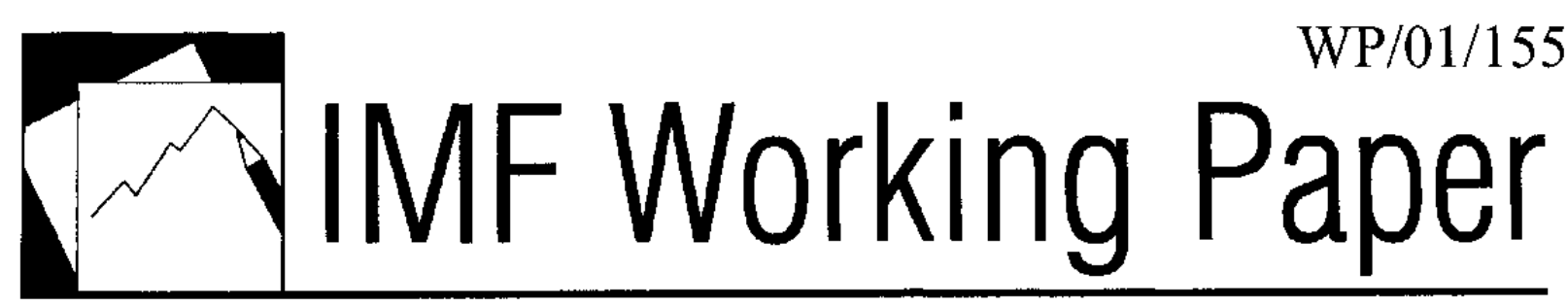

Why Has the Euro Been So Weak?

Guy Meredith 


\title{
IMF Working Paper
}

\author{
Research Department
}

\section{Why Has the Euro Been So Weak?}

\author{
Prepared by Guy Meredith ${ }^{1}$ \\ Authorized for distribution by Kenneth Rogoff
}

October 2001

\begin{abstract}
The views expressed in this Working Paper are those of the author(s) and do not necessarily represent those of the IMF or IMF policy. Working Papers describe research in progress by the author(s) and are published to elicit comments and to further debate.
\end{abstract}

The weakness of the euro has been surprising given the widely-held expectation that it would be a strong currency. This paper critically examines explanations for the slide in the euro, finding that many are questionable on conceptual or empirical grounds. Two explanations are instead advanced that appear to be consistent both with theory and data. The first originates in the global surge in equity prices since the mid-1990s, which created a demand shock that disproportionately affected the U.S. economy. Model simulations indicate that this can explain the strength of the dollar against other currencies in recent years, accounting for about half of the decline in the effective value of the euro. The other component of euro weakness can be attributed to a mismatch between the demand and supply of eurodenominated assets that arose with the creation of the single currency in 1999. The effect of both these factors should fade over time, although near-term market volatility could be exacerbated by uncertainties about the fundamentals driving currency values.

JEL Classification Numbers:F31; F41; F47

Keywords: exchange rates, equity prices, euro weakness

Author’s E-Mail Address: gmeredith@imf.org

${ }^{1}$ This paper has benefited significantly from comments by several colleagues in the European I and Research Departments, and participants in a seminar at the European Central Bank. 


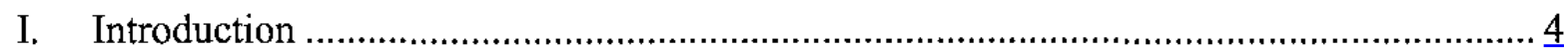

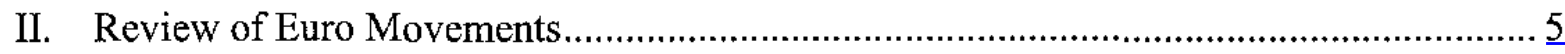

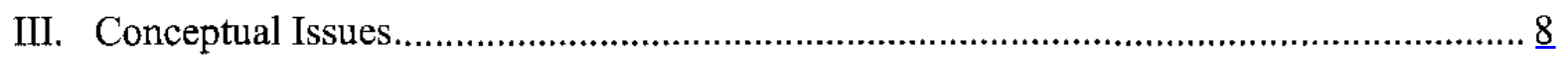

IV. Explanations for Euro Weakness............................................................................

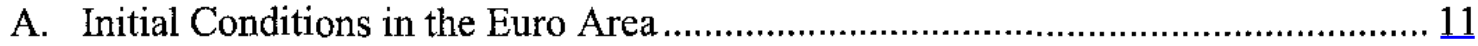

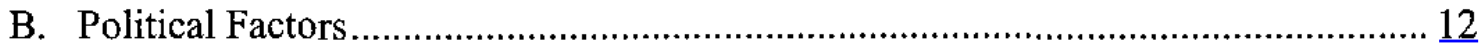

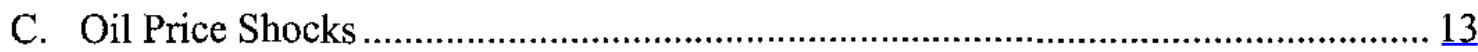

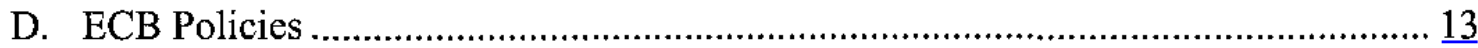

E. "New Economy" Phenomena ........................................................................ 15

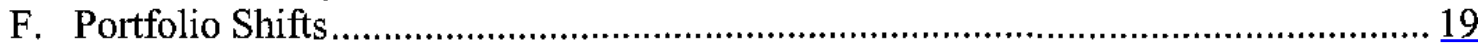

G. Nonfundamental Market Dynamics ............................................................... 20

V. Equity Markets and the Euro/Dollar Rate ……..................................................... 20

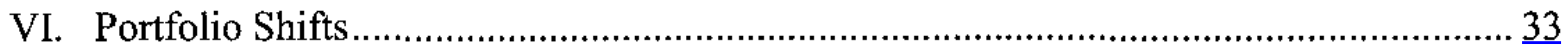

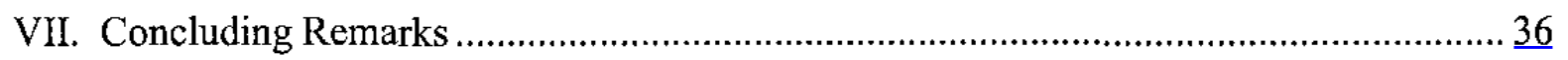

Table

1. Euro Weakness in Historical Terms ................................................................... 7

Figures

1. Real and Nominal Euro Rates Versus U.S. Dollar ..................................................... $\underline{6}$

2. Euro Real Effective Exchange Rate Measures ............................................................. 6

3. Projected GDP Growth Rate Differential and Euro/Dollar Exchange Rate ................... 16

4. Long-Term Government Bond Yield Differentials .................................................... $\frac{16}{16}$

5. Current Account Balances (Excluding oil trade) ........................................................ 18

6. Productivity Growth and Changes in the Euro ...................................................... 18

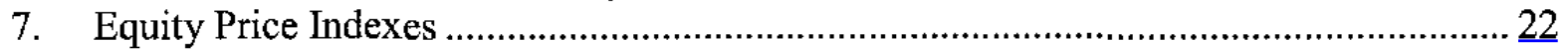

8. Equity Market Capitalization Rations..................................................................... 22

9. Differences in Equity Market Capitalization Rations ............................................... 22

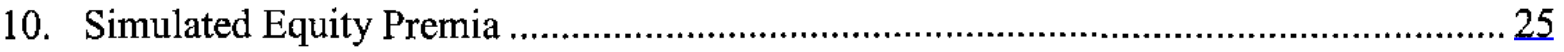

11. Simulated Market Capitalization and Exchange Rate …………………..................... 25

12. Simulated Output and Output Gaps .................................................................... 26

13. Simulated Trend Labor Productivity Growth ............................................................ 26

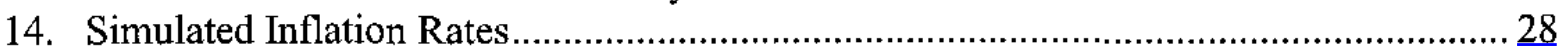

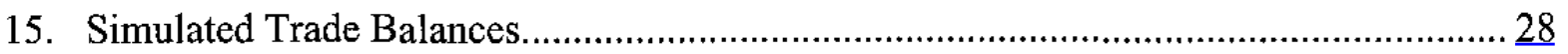

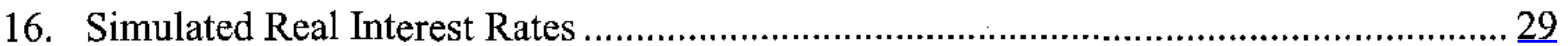

17. Simulated Market Capitalization and Exchange Rate: Permanent ................................ 29

18. Market Capitalization and Exchange Rate: Productivity Shock ................................... 31 
19. Simulated Market Capitalization and Exchange Rate: Zero Equity

Premium in 2001

20. New Issues of Euro-denominated Debt Securities................................................... 34

21. Euro-denominated Share of International Debt Issues ............................................ 34

22. Simulated Euro Exchange Rate: Shock to Excess Yield .......................................... 37

23. Simulated Real Interest Rates: Shock to Euro Excess Yield ..................................... $\underline{37}$

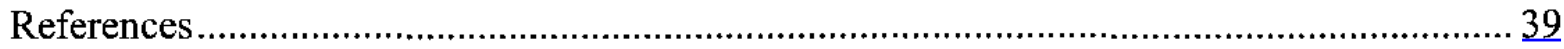

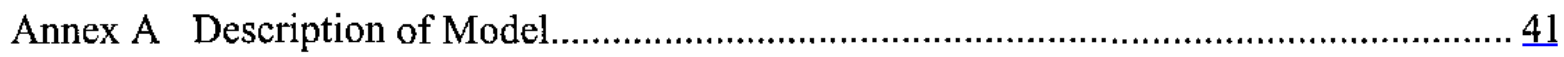

Annex Table

A.1. Model Mnemonics and Variable Definitions........................................................ 43 


\section{INTRODUCTION}

The decline in the value of the euro since its introduction in 1999 has been one of the most problematic aspects of the single-currency project. Not only has it been a source of popular concern in Europe, especially given already mixed enthusiasm for the new currency, but it has also complicated life for policymakers. The falling exchange rate, combined with oil and food price shocks, has fuelled inflation as real growth has weakened, constraining the scope for monetary easing. It has also raised the issue of whether exchange-market intervention is justified to correct for market distortions.

From an analytical perspective, the weakness in the euro is of interest in light of the energy devoted to predicting its future course prior to 1999. Although opinions were varied, the majority view seems to have been that the euro would more likely appreciate than depreciate. In any event, nobody appears to have anticipated the magnitude and speed of the decline, representing another inglorious chapter in attempts to forecast exchange rates.

Of course, explaining exchange rate movements ex post is less difficult than forecasting them, and there has been no shortage of rationalizations for the euro's decline. Initially, it was ascribed to a natural reversal of its strength in late 1998, and not viewed with great concern. As time passed, however, and the euro fell below 1997-98 lows, the search for more fundamental explanations began. This paper lays out and assesses many of the hypotheses that have been advanced for euro weakness. For the most part the analysis is conducted in terms of the exchange rate vis-à-vis the U.S. dollar. This comparison is emphasized for two reasons. First, the movement in the euro-dollar rate has been particularly dramatic, reflecting as it does a combination of both euro weakness and dollar strength against other currencies. Second, the market rationalization for these exchange rate developments often has involved a contrast between the structure and performance of the euro-area and U.S. economies.

To summarize the conclusions, much of the weakness of the euro reflects the strength of the dollar against most other currencies, which began prior to the introduction of the single currency itself. We associate this component with the surge in equity market capitalization in the U.S. since the mid-1990s, which led to a large positive demand shock in the U.S. and consequent currency appreciation. The second component reflects weakness in the euro against most other currencies beginning in 1999. This appears to reflect a change in capital market activity associated with the introduction of the euro. Specifically, issuance of eurodenominated debt by borrowers from outside the region surged, while euro-area borrowers replaced foreign-currency debt with euro issues. This shift was likely reinforced by euro-area lenders diversifying into non-euro assets. These shifts would have increased the supply of euro assets relative to demand, depressing the exchange rate.

More recently, the surge in U.S. equity market capitalization has partially corrected with the decline in equity prices from peaks in 2000, creating scope for some reversal of euro weakness. Of course, the role of this factor also depends on the future course of equity prices, 
which is subject to considerable uncertainty. Regarding portfolio shifts, it is likely that the effects will fade over time, as asset stocks and international interest-rate differentials adjust. In the near term, though, these "fundamentals" may well be dominated by speculative market activity, as uncertainty about the underlying determinants of exchange rates has probably risen in the face of large observed movements in the euro/dollar rate.

The paper is structured as follows. The next section discusses past movements in the euro and estimates of its equilibrium level. The third section presents a conceptual framework for analyzing currency movements, while the fourth section reviews various explanations for euro weakness. The main hypotheses for euro weakness are presented in the fifth and sixth sections, involving the surge in U.S. equity valuations and shifts in portfolio behavior in the euro area respectively. The paper ends with concluding observations.

\section{REviEw OF EuRo Movements}

Figure 1 shows the nominal and real (CPI deflated) euro/dollar exchange rates since 1979. Prior to 1999 , these are based on weighted averages of the legacy currency rates vis-àvis the dollar. The series move closely together, reflecting the absence of a sustained inflation differential. It can be seen that the decline in the euro since early 1999 continues a trend that began in 1995. Since that time, the euro has depreciated by about 35 percent against the dollar. Against this underlying trend, the strength of the euro in late 1998 can be seen as a short-lived blip.

Looking further back, the value of the euro in 1995 was somewhat above its average of the previous 10 years, but not dramatically so (about 5 percent). Including the first half of the 1980s, the euro looks more appreciated in 1995, but exchange rates among the major currencies in the early 1980 s reflected a significant overvaluation of the U.S. dollar, distorting the comparison. Indeed, the trough reached by the euro against the dollar in 1984 was almost 20 percent weaker than the mid-2001 rate, indicating that recent swings are not unprecedented by historical standards.

Another perspective on euro movements is provided by Figure 2, which shows the real effective value of the euro, and also the effective measure excluding the U.S. dollar and pound sterling. In real effective terms, the euro has depreciated by about 20 percent since 1995-slightly more than half as much as the decline in the euro/dollar rate. The smaller movement in the effective index, of course, reflects the strength of the dollar against other currencies, notably the yen. Indeed, the real effective value of the euro excluding the dollar and sterling was rather steady from 1995 to 1998 , and only began to depreciate significantly with the introduction of the single currency in 1999. Since 1995, this narrower measure of the effective rate has declined by about 10 percent. Taking this 10 percent decline as being 
Figure 1. Real and Nominal Euro Rates Versus U.S. Dollar

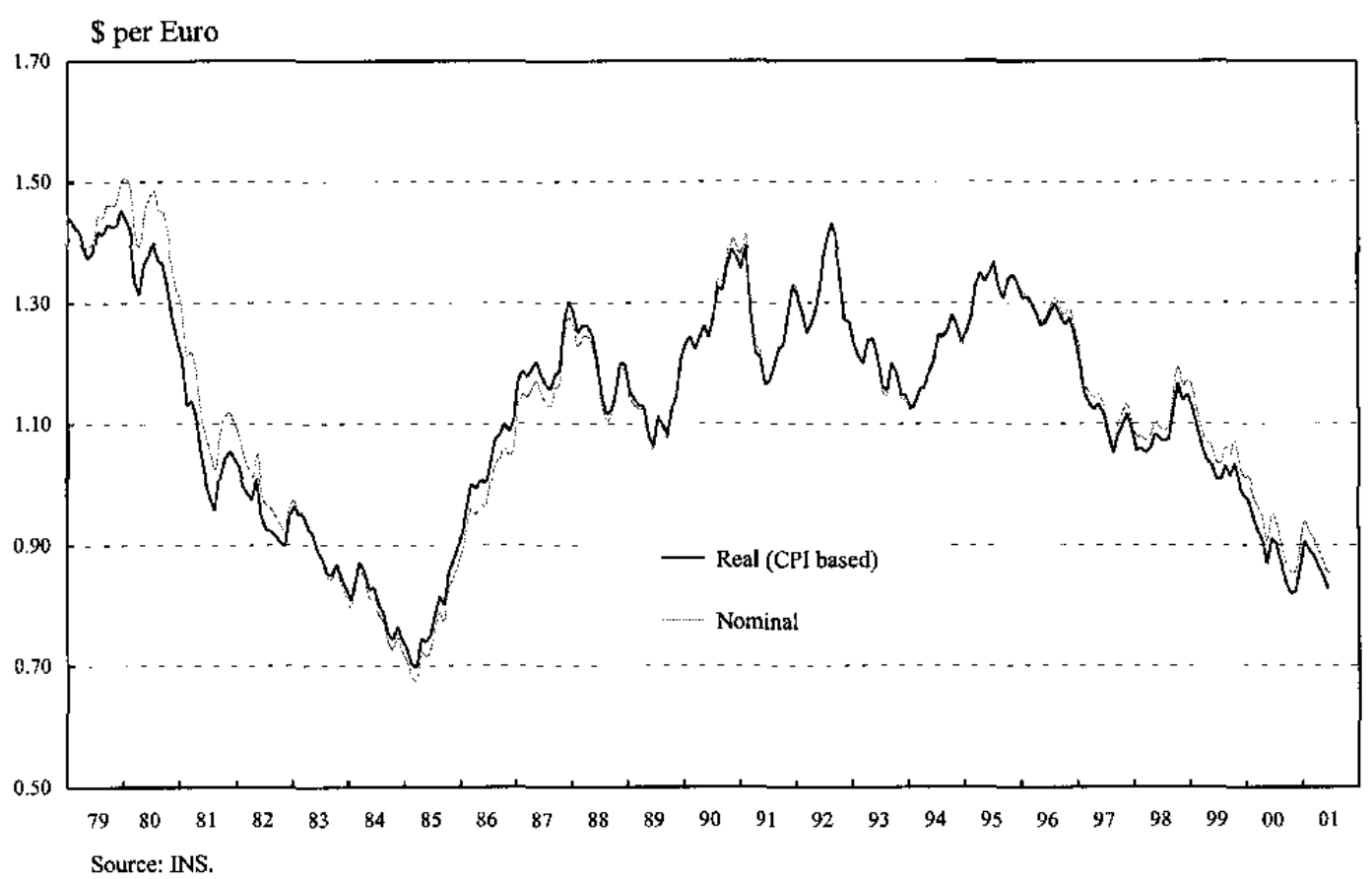

Figure 2. Euro Real Effective Exchange Rate Measures

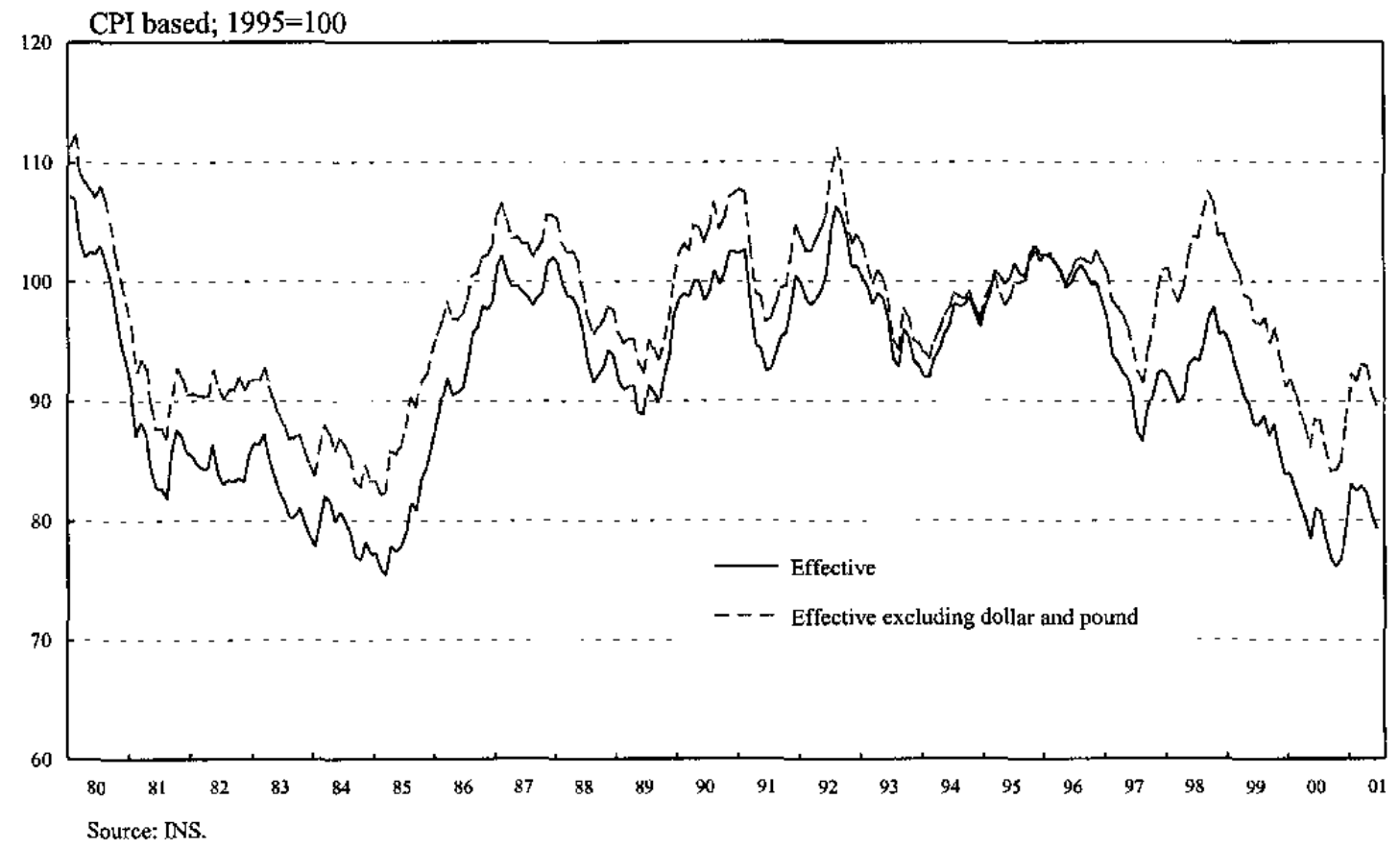


the component that is specific to the euro, and removing it from the overall depreciation of 20 percent since 1995 , leaves a component that reflects dollar strength of another 10 percent. ${ }^{2}$

Compared with the trough in 1984 , the real effective value of the euro in mid-2001 is slightly higher, but the gap is less than for the euro/dollar bilateral rate. In any event, both measures indicate that the euro is well below normal historical levels, although the deviation is not as large as in 1984.

Table 1. Euro Weakness in Historical Terms (percent change to first half of 2001)

\begin{tabular}{|l|c|c|}
\hline & Real euro/dollar & Real effective (CPI) \\
\hline 1984 low & $+17 \%$ & $+6 \%$ \\
\hline $1986-95$ average & $-28 \%$ & $-16 \%$ \\
\hline 1995 & $-34 \%$ & $-19 \%$ \\
\hline 1999 (January) & $-23 \%$ & $-14 \%$ \\
\hline Note: 2001 HI average euro/dollar rate $=0.873$. \\
\hline
\end{tabular}

Most empirical studies of the equilibrium level of the euro conclude that the currency is substantially undervalued from a medium-term perspective. As surveyed in Koen and others (2001), equilibrium estimates of the bilateral rate against the dollar are centered on a range of about $\$ 1.15-1.20$ per euro, similar to the rate at which the euro was introduced. There are outliers, of course, with isolated estimates ranging from $\$ 0.87$ per euro on the weak side to $\$ 1.45$ on the strong side. On balance, though, there is a broad consensus that, at $\$ 0.85$, the euro would be undervalued against the dollar by some 25-30 percent. Staff calculations based on a medium-term macroeconomic balance approach are consistent with these estimates: at mid-2001 exchange rate levels, the euro is judged to be undervalued against the dollar by over 25 percent.

This review of euro developments can be summarized as follows:

- the weakening in the euro against the dollar began in 1995 from a level that does not appear overvalued by historical standards;

2 This is consistent with the appreciation of the dollar against currencies other than the euro of about 25 percent over this period, which would translate into a decline in the euro's effective value of about 10 percent given the dollar's weight. 
- the euro remained broadly stable against currencies other than the dollar and the pound during 1995-98;

- since 1999, the euro has declined against most other currencies, as well as the dollar;

- of the 20 percent depreciation in the real effective value of the euro since 1995 , about one half reflects the rise in the value of the dollar against other currencies, while the other half reflects weakness specific to the euro.

\section{Conceptual Issues}

A common difficulty in evaluating explanations for exchange rate movements is that the underlying framework is not clear. Explanations that are viewed as independent are often different aspects of the same phenomenon. Others involve theoretical inconsistencies, or the magnitude of the effect to be explained is at variance with conventional parameter estimates. Thus it is useful to start with a conceptual framework for assessing explanations for euro weakness.

Much of the difficulty in understanding exchange rates follows from their complex economic role. Exchange rates affect the relative price of domestic and foreign output, and thus trade competitiveness. They are also, of course, influenced by capital flows. Both the trade and capital account relationships, in turn, depend importantly on inter-temporal factors, including real interest rates. Real interest rates across countries reflect, among other things, expected real exchange rate movements. As a result, the determination of real exchange rates, real interest rates, and trade and capital flows is circular, and heavily dependent on views of the future. As expectations are inherently subjective, so are key factors determining exchange rates. The issue then becomes one of judging the plausibility of the implied expectations associated with a given level of the exchange rate.

These issues can be considered more concretely via an equation relating the expected change in the exchange rate to the interest differential on home- versus foreign-currency assets, and the expected "excess" return on home-currency assets:

$$
e r_{t, t+1}^{e}-e r_{t}=-\left(i_{t}-i_{t}^{*}\right)+\varepsilon_{t}
$$

The variable er is the foreign-currency price of domestic currency (thus an increase indicates domestic appreciation); $i$ is the one-period interest rate on domestic assets; $i^{*}$ is the rate on foreign assets, and $\varepsilon$ is the expected excess return on domestic assets. This equation is an identity assuming that covered interest parity holds. ${ }^{3}$ The expected change in the exchange

3 Covered interest parity requires that the intercst differential equal the gap between the forward exchange rate quoted in futures markets and the spot rate. The difference between the expected future rate and the forward rate then corresponds to the expected excess return. 
rate and the interest differential can be expressed either in nominal or real terms, as equation (1) can be transformed from the former to the latter by subtracting expected inflation from both sides. Generally speaking, we will view this relationship in real terms.

Equation (1) presents problems in analyzing the determinants of the current exchange rate, as it includes the next-period (unobserved) expectation. This expectation is likely to be highly correlated with the current-period rate, and affected by similar factors. The nextperiod value can be iteratively substituted out, however, allowing the level of the exchange rate in some initial-period 0 to be expressed as a function of the initial interest differential and expected excess yield, the sum of their future values out to some distant point $T$, and the value of the exchange rate at that time:

$$
e r_{0}=\left(i_{0}-i_{0}^{*}\right)-\varepsilon_{0}+\sum_{j=1}^{T}\left(i_{j}^{e}-i_{j}^{*}, e\right)-\sum_{j=1}^{T} \varepsilon_{j}^{e}+e r_{T}^{e}
$$

The advantage of this approach is that the expected value of the exchange rate at time $T$ can more plausibly be assumed to be independent of cyclical and other transitory influences; this is particularly true when the equation is viewed in real terms.

Looking at equation (2), it is not surprising that it is difficult to understand exchange rate behavior. The only directly observable determinant is the current interest differential. The other right-hand side variables are unobservable, and in practice have an influence that vastly exceeds that of the current interest differential. ${ }^{4}$ Things can be simplified somewhat, though, by assuming that long-term interest rates reflect expected future short rates, allowing the short-term differential to be collapsed into the current long-term differential:

$$
e r_{0}=\left(i l_{0}-i l_{0}^{*}\right)-\varepsilon_{0}-\sum_{j=1}^{T} \varepsilon_{j}^{e}+e r_{T}^{e}
$$

where $i l$ is the long-term rate on assets of duration $T$.

Equation (3) suggests a "capital-flows-centric" view of exchange rate movements, as the exchange rate is a function of asset yields: it is not clear how trade considerations enter the picture. To close the framework, relationships are needed that relate the long-term interest rate to the exchange rate, and also determine the "terminal" exchange rate at time $T$. In a stylized way, these can be represented as:

$$
y-\bar{y}=f\left(\stackrel{(-)}{e r}, \stackrel{(-)}{i l}, \stackrel{(\ell)}{f}^{f}-\vec{y}, z\right)
$$

4 The standard deviation of annual exchange rate movements among large industrial countries is, on average, five times greater than that of interest differentials (Meredith (2001)). 


$$
i l=g\left(y^{(+)} \bar{y}\right)
$$

where $y$ is a measure of economy-wide output, $\bar{y}$ is some potential level of $y, y^{f}$ is foreign output, and $z$ is a set of other factors that affect aggregate demand. These relationships are shown for the home economy; similar ones will apply to the foreign economy. Equation (4) indicates that output depends negatively on the exchange rate and the long-term interest rate, while (5) shows that the long-term rate rises when output increases above its potential level. There are more detailed stories that could be told to motivate these relationshipsparticularly the second-but they are not needed for present purposes. ${ }^{5}$

Trade flows affect the exchange rate in the short and medium run through their impact on output and thus interest rates. In the long run, when output returns to potential and long-term interest rates are equal across countries, the exchange rate is determined by solving equation (4) when $y-\bar{y}$ is zero. Demand factors, $z$, directly affect activity, and through this channel the interest differential, and then the exchange rate. What can broadly be described as "portfolio effects"-i.e. differences in expected yields on currencies-are incorporated in the $\varepsilon$ terms. Finally, long-term fundamentals are captured in $e r_{T}^{e}$, which reflects the long-run solution to equation (4).

How can the common view that differences in real growth rates between countries drive exchange rates be reconciled with this framework? Faster growth that reflects a positive demand shock ( $z$ ) will boost output relative to potential, raising real interest rates. Higher real interest rates draw in foreign capital, causing the exchange rate to appreciate. Faster real growth that results from a shock to potential growth $(\Delta \bar{y})$ can also boost aggregate demand via higher investment and consumption, with similar effects on interest rates and the exchange rate. In the long run, however, the effect of sustained growth in potential output could well be the reverse: a higher level of $\bar{y}$ relative to $y^{f}$ would require a depreciation of the exchange rate in order to equate global demand and supply for domestic output. ${ }^{6}$

The expected excess yield, $\varepsilon$, in equation (3) warrants some discussion. Differences between expected yields on assets can be attributed to some combination of imperfect asset substitutability and/or investor risk aversion. These are sometimes referred to as "portfolio effects", and can lead to a perverse relationship between interest rates and the exchange rate. For instance, an increase in $\varepsilon$ will cause the exchange rate to depreciate, boosting domestic activity and interest rates-thus, the exchange rate will fall at the same time as interest rates

5 A more detailed discussion of these conceptual issues is contained in IMF (1998). Adding stickyprice dynamics via an inflation equation would not alter the underlying story.

6 As discussed in the next section, this effect depends on the source of the productivity shock. A shock concentrated in the traded-goods sector could instead lead to exchange rate appreciation via Balassa-Samuelson effects. 
rise. In practice, such portfolio effects are not directly observable because market expectations of the future exchange rate are not known. So their role in explaining exchange rate movements can only be inferred. An increase in the supply of assets denominated in the home currency, for example, will raise $\varepsilon$ and depreciate the exchange rate if home and foreign currency assets are imperfect substitutes. An increase in exchange rate volatility would also affect $\rho$ if investors are risk averse, but the sign of the effect is uncertain. Generally speaking, the risk premium will rise on the currency in which international investors have a net long position, as they reduce their exposure to currency fluctuations.

To summarize, this framework relates the current level of the exchange rate to current and expected future interest rates, exchange risk premia, and the long-run equilibrium value of the exchange rate. It shows why pinning down the causes of exchange rate movements is difficult-specifically, because these factors are largely unobservable. Nevertheless, the framework imposes useful structure by identifying the channels through which various factors play a role. The empirical plausibility of explanations can then be judged in terms these structural linkages, and their consistency with other macroeconomic phenomena.

\section{EXPLANATIONS FOR EURO WEAKNESS}

Many explanations have been advanced for why the euro is weak, which we categorize here under broad headings before a more specific discussion:

- initial conditions in the euro area (e.g., labor market rigidities);

- political factors (e.g., the Danish referendum);

- world oil price shocks;

- ECB policies (uncertainties, and/or an anti-growth bias);

- contrast with U.S. "new economy" (e.g., productivity growth);

- portfolio shifts (e.g., increased international issuance of euro-denominated bonds);

- nonfundamental market dynamics (e.g., herd behavior).

\section{A. Initial Conditions In The Euro Area}

Structural weaknesses in euro-area economies are often perceived as undermining the currency. Examples are labor market rigidities; the size of welfare states; and difficulties in establishing sound fiscal policies. All of these features, however, are long-standing (de Grauwe (2000)). In order to explain the recent weakening of the euro, one would have to argue that there were unfavorable surprises that caused markets to become more pessimistic in the last few years. Yet the general picture has been one of continued progress in structural reforms in the euro area, and at a pace that is not unfavorable compared with past experience. So it is difficult to reconcile the timing of the weakness with these underlying factors. 
This suggests a more provocative hypothesis: that structural reforms are actually bad for the euro. Looked at in terms of the theoretical framework, this view is at least as plausible as the conventional one. Structural reforms boost growth, but supply-driven growth does not unambiguously boost the currency. Indeed, in the longer term, the domestic currency is expected to fall in order that more domestic output can be sold abroad. In any event, while theoretically intriguing, this hypothesis is also implausible empirically. An appreciable impact on euro-area productivity growth would be needed relative to that in other countries for structural reforms to explain either a rise or fall in the currency. But there has been no such marked change in euro-area productivity growth.

Another initial condition is the possible overvaluation of the deutsche mark when the conversion rates of the EU-11 currencies were established. Germany was experiencing the after-effects of the positive demand shock arising from reunification at that time. To the extent that the strong deutsche mark was associated with a general overvaluation of the euro, one might argue that its subsequent weakness reflects a reversal of an initial misalignment. This view, however, is not consistent with the stylized facts, which suggest that the synthetic euro was not overvalued in 1995, when it began to weaken against the dollar. The deutsche mark itself was relatively strong, but this was offset by weakness in some other euro-area currencies following the 1992-93 ERM crisis. Overall, the synthetic euro was roughly in line with historical values.

\section{B. Political Factors}

Some commentators have focused on political events surrounding the future of the euro area as explaining the weakness in the currency. Examples are the "no" vote in the Danish referendum on membership; the U.K. decision to continue to stay out; and general uncertainties about enlargement and the future size of the euro area. In this sense, the euro project as a whole is sometimes regarded as being incomplete in political as opposed to economic terms. The difficulty with these explanations is that there is no fundamental reason to expect them to be related to currency weakness. There is nothing inherent in the size of a region that determines its currency value. Small countries, such as Switzerland, can have strong currencies, as can large countries such as the U.S. In terms of the implications for monetary policy formulation, there is no presumption that including other countries would either weaken or strengthen policies. Of course, these political events have occurred in conjunction with the decline in the euro, but so have many other factors. If anything, to the extent there is causation, it seems more plausible to suppose that euro weakness has reinforced aversion to joining the area rather than the opposite.

The war in Kosovo and other disturbances in the Balkans have also been mentioned as justifying a flight from the euro for safe-haven reasons. The situation in the Balkans has stabilized, however. More fundamentally, the deutsche mark is a common safe-haven currency in eastern Europe. Political disturbances in the region might plausibly be expected to boost demand for "hard" deutsche marks and thus raise the value of the euro, rather than the reverse. 


\section{Oil Price Shocks}

The decline in the effective value of the euro during 1999-2000 appears to correlate well with the surge in global oil prices (OECD (2001), Chapter IV). An inverse relationship is natural given that the euro area is a net oil importer and thus higher oil prices imply a negative terms of trade shock. How much of the euro depreciation could plausibly be explained by this factor? Model simulations suggest that only a small component of the euro weakness is attributable to the effects of higher world oil prices on trade flows. Hunt and others (2001) simulate the effects of a 50\% rise in world oil prices, and find a depreciation in the real effective value of the euro of less than 2 percent; against the dollar, the euro falls by only 1 percent. The absence of a large effect on the euro/dollar rate is not surprising, given that the net oil imports of the euro area were only slightly higher than those of the United States. $^{7}$

Another facet of the story involves asset market effects associated with higher oil prices-specifically that oil exporters tend to recycle receipts into U.S. dollars rather than euros. Higher receipts then translate into higher world demand for U.S. assets, pushing up the dollar. No direct evidence has been produced on such an effect, however. Furthermore, two aspects of the experience tend to cast doubt on its importance. The first is that the portfolio shift and the associated dollar movements would be correlated with the cumulative flows of revenues of oil exporters, as opposed to spot oil prices themselves. The second is that the previous experience with global oil price shocks does not yield the same pattern of currency movements as observed in 1999-2000.

\section{ECB Policies}

An often-cited view in markets is that opacity in ECB policy-making has undermined the currency. Changes in policy have sometimes come as surprises, with explanations that are perceived as unclear. Theoretically, policy uncertainty could have an effect through increased in the volatility of financial variables such as exchange rates and interest rates. To the extent that investors are risk-averse, such volatility could affect risk premia in exchange markets. The effect on the level of the exchange rate, though, is ambiguous. Volatility in a bilateral exchange rate, such as the euro/dollar rate, creates uncertainty for agents in both countries. In general, it will prompt them to reduce their exposure to currency movements by reducing their foreign-currency assets and liabilities. The net impact on the exchange rate then depends on the initial (net) exposures. If the home country is a net creditor in foreign assets, the home-country currency will tend to appreciate as uncertainty rises. Net foreign asset data indicate that the euro region is a net international creditor, whereas the United States is a debtor. Assuming this picture also broadly holds on a bilateral basis, greater exchange rate uncertainty would cause euro-region residents to reduce their U.S. dollar assets, and U.S.

${ }^{7}$ Net oil imports of the euro area were about 0.7 percent of GDP in 1998 compared with 0.5 percent for the U.S. 
borrowers to reduce their euro liabilities. These portfolio shifts would cause the euro to appreciate, opposite to the conventional view.

Another factor conflicting with this view is the pre-1999 experience, when monetary policy in the euro region was guided by the Bundesbank. Like the ECB, the Bundesbank was not perceived by markets to follow a particularly predictable policy course. Yet this was not viewed as contributing to weakness in the deutsche mark, which instead was viewed as a notably "hard" currency. In a different context, uncertainty about movements in the yen/dollar rate seems to be a factor that has strengthened the yen by encouraging Japanese investors to keep their assets in yen, in spite of wide interest differentials in favor of foreign currencies.

Another school of thought is that ECB policy has generally been too tight. Tight policies, it is argued, have undermined future real growth in the region, in turn depressing the value of the euro. The converse is held to be true for Fed policy-by boosting U.S. growth, interest rate cuts have supported the dollar. If this were true, it would have important implications for policies. For instance, euro-area interest rate cuts could have a beneficial (short-term) effect on inflation by causing euro appreciation and lowering traded-goods prices.

However, this view is inconsistent with the pre-euro experience. The Bundesbank was widely perceived to be a conservative central bank with a pronounced anti-inflationary bias, yet the deutsche mark was a strong currency. Conceptually, it also encounters important difficulties. The first is that future growth, per se, does not influence exchange rates; rather, its impact is felt through changes in long-term interest rates. ${ }^{8}$ Monetary easing that causes future growth to rise would have to cause long-term real interest rates to rise at the same time to explain exchange rate appreciation; monetary tightening would have to cause long-term real rates to fall. These effects are contrary to the expected impact of monetary policy on real interest rates, and also to the responses predicted by standard macroeconomic models. ${ }^{9}$

The actual experience is also not supportive. There were ten changes in the ECB's policy interest rate from 1999 through end-August 2001. Regressing the percent change in the effective exchange rate from the day before the policy change to six days after on the change in the interest rate yields a slope coefficient of 1.17 with a t-statistic of 1.6 . This indicates that a one percentage point rise in the interest rate has been associated with euro

8 Growth could also affect the current exchange rate through its impact on the expected long-term rcal exchange rate. A monetary shock, however, would not be expected to influence long-term real variables, including the exchange rate.

9 See, for instance, Bryant and others (1993). 
appreciation of slightly over 1 percent, with the effect being marginally significant. The sign and size of the parameter are consistent with conventional stories of interest-rate effects. ${ }^{10}$

\section{E. "New Economy" Phenomena}

Many aspects of economic developments since the mid-1990s have been attributed to the birth of a "new economy." The new economy is viewed as arising from a surge in productivity growth due to factors such as the permeation of information technology, along with structural changes such as greater competition in product and labor markets. The persuasiveness of this view rose along with persistent upward revisions to U.S. GDP growth over this period, while inflation was generally lower than expected. The euro area, in contrast, is viewed as lagging in these respects, explaining the difference in growth performance.

From an exchange rate perspective, there is indeed a correlation between revisions to projected growth for the U.S. and the euro area and movements in the euro/dollar rate (Figure 3). ${ }^{11}$ As discussed above, this correlation could arise through interest rate channels. Faster productivity growth, for instance, can increase aggregate demand, both because investment demand rises and because households consume more in expectation of higher future incomes. ${ }^{12}$ This demand effect will tend to push up real interest rates and thus the exchange rate in the faster growing economy, at least in the short run. In support of such a demand effect, there is evidence of a widening in long-term interest-rate differentials between the U.S. and the euro area. As shown in Figure 4, the gap between U.S. and German bond yields swung from about -25 basis points in the early 1990 s to over 100 basis points by $2000 .{ }^{13}$ The shift in spreads between U.S. treasuries and an aggregate of euro-area bond yields was even more pronounced, but this may reflect other factors, including declines in currency risk and inflation expectations in countries such as Italy. In any event, assuming that

${ }^{10}$ Similarly, regressing the change in the yield on index-linked French government bonds on that in the policy interest rate yielded a coefficient of 0.064 with a t-statistic of 1.3 , indicating that real long-term interest rates tend to rise when monetary policy is tightened.

${ }^{11}$ Corsetti and Pesenti (1999) appear to have first uncovered this relationship.

12 Bailey and others (2001) have a lucid discussion of these effects in the context of a stylized model.

13 The "adjusted" yield spread reflects the increase in the spread betwcen yields on U.S. corporate bonds and treasuries, and is intended to adjust for the effect of a reduced supply of treasuries on market yields in 1999-2000 (see Schinasi and others (2001)). 
Figure 3. Projected GDP Growth Rate Differential and Euro/Dollar Exchange Rate 1/

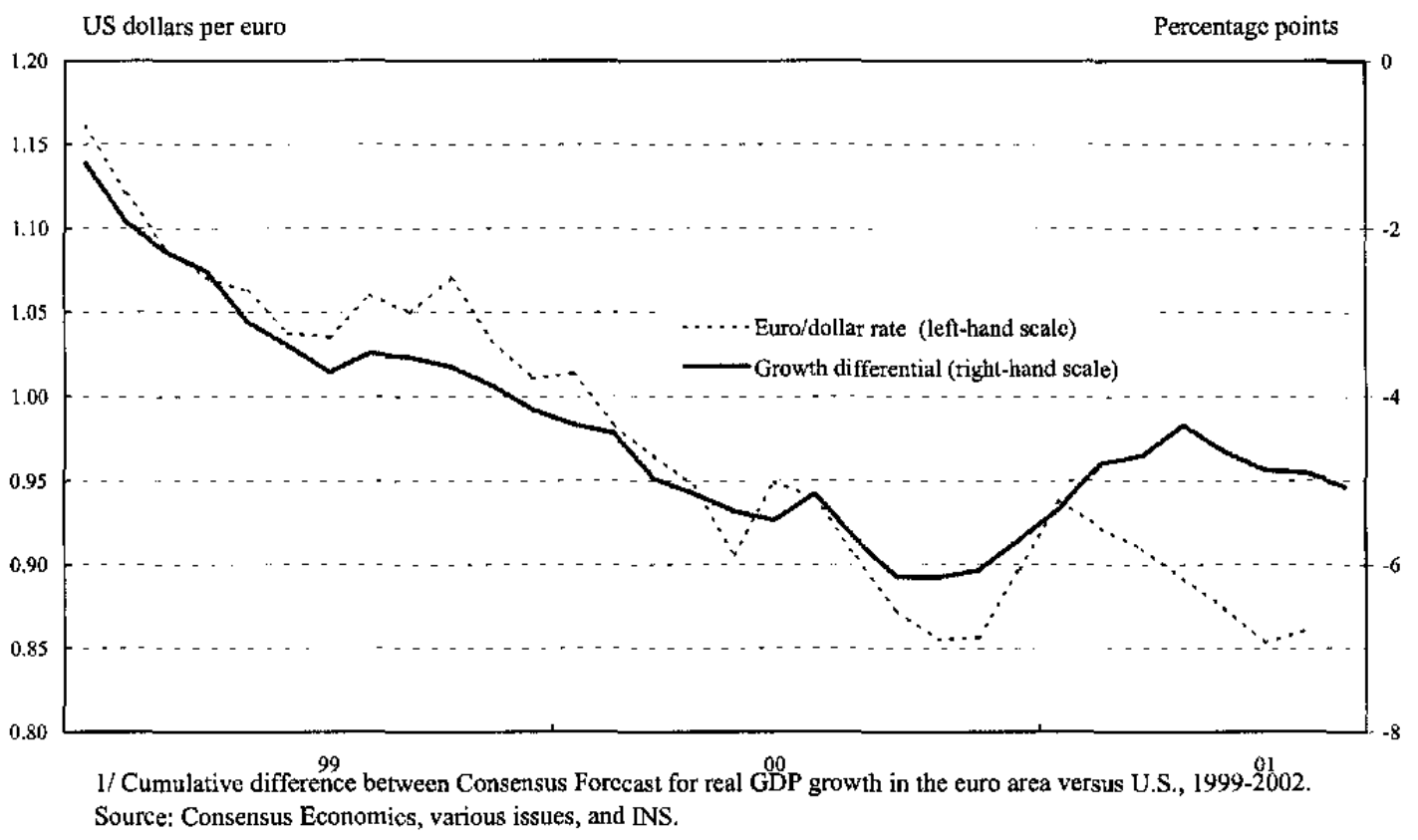

Figure 4. Long-Term Government Bond Yield Differentials

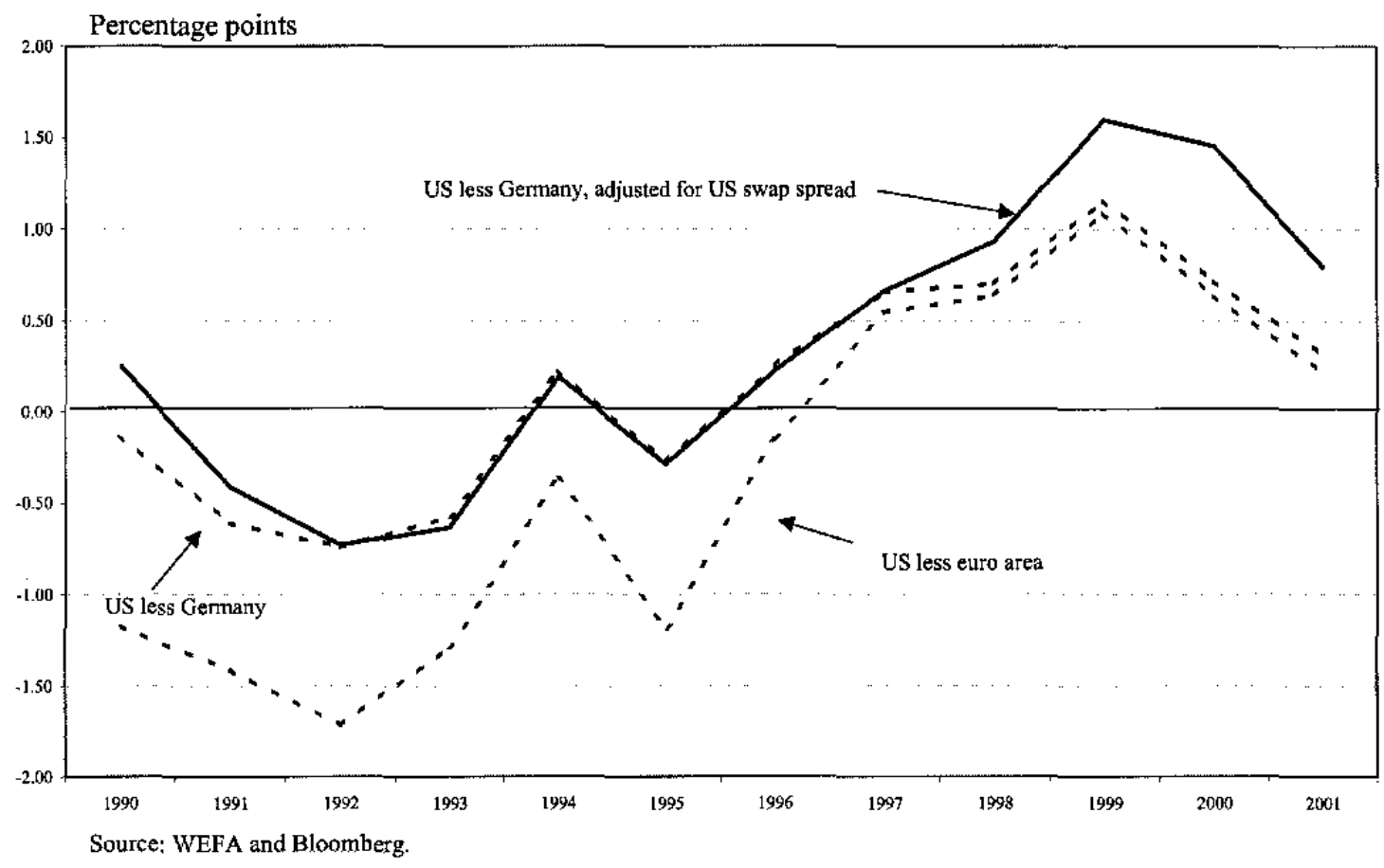


long-term inflation expectations were relatively stable, there appears to have been a significant shift in real interest differentials in favor of U.S. assets. ${ }^{14}$

At the same time as the interest rate differential widened in favor of U.S. assets and the dollar appreciated against the euro, the U.S. current account deficit rose sharply relative to that in the euro area (Figure 5). This combination of phenomena points to a substantial positive shock to aggregate demand in the U.S. relative to the euro area. ${ }^{15}$ Furthermore, the restrained behavior of U.S. inflation in the face of an acceleration in output growth suggests that this demand shock was accompanied by a positive supply shock in the U.S. The underlying cause could be a productivity growth shock, or some other factor that led to both higher demand and supply. These possibilities are analyzed in the next section.

A different explanation has been advanced for why productivity growth would affect the euro/dollar exchange rate that relies on long-run supply effects rather than short-run demand factors. Specifically, if faster productivity growth is concentrated in the traded-goods sector, and traded goods are perfect substitutes internationally, then the faster-growing economy should experience long-run exchange rate appreciation (the Balassa-Samuelson effect). In support of this story, Figure 6 shows a close correlation since the early 1990s between the lagged difference between euro-area and U.S. labor productivity growth and the change in the euro/dollar exchange rate. ${ }^{16}$

The Balassa-Samuelson explanation runs into problems with other aspects of the evidence, however. One is that the magnitude of the effect would need to be much greater than results obtained for other countries, with the euro/dollar exchange rate moving by over 3 times as much as the productivity growth differential. Typical estimates (and theoretical considerations) suggest that this ratio should be at most unity. ${ }^{17}$ Using the upper limit for this ratio, Tille and others (2001) find that the Balassa-Samuelson effect could account for a depreciation of the euro against the dollar of about 1 percent per year during the $1990 \mathrm{~s}$.

14 Measures of inflation expectations from consensus forecasts and, more recently, break-even inflation rates from index-linked bonds, suggest that longer-term expectations were indeed relatively stable over this period.

15 These phenomena are also consistent with another facet of the "new economy" story: that high returns on U.S. investment have attracted foreign capital, driving up the exchange rate through capital account effects. Indeed, balance of payments data show a rise in direct investment by euroarea residents in the U.S. in recent years. Furthermore, empirical studies indicate a significant correlation between these capital flows and exchange rate developments (IMF (2001), Chapter II).

${ }^{16}$ See Owen (2001).

${ }^{17}$ DeBroeck and Sløk (2001) find, for instance, an avcragc response of the real exchange rate to GDP growth of 0.4 for non-transition countries. Bailey and others (2001) simulate a stylized model to derive roughly the same ratio of exchange rate movements to productivity changes. 


\section{Figure 5. Current Account Balances}

(Excluding oil trade)

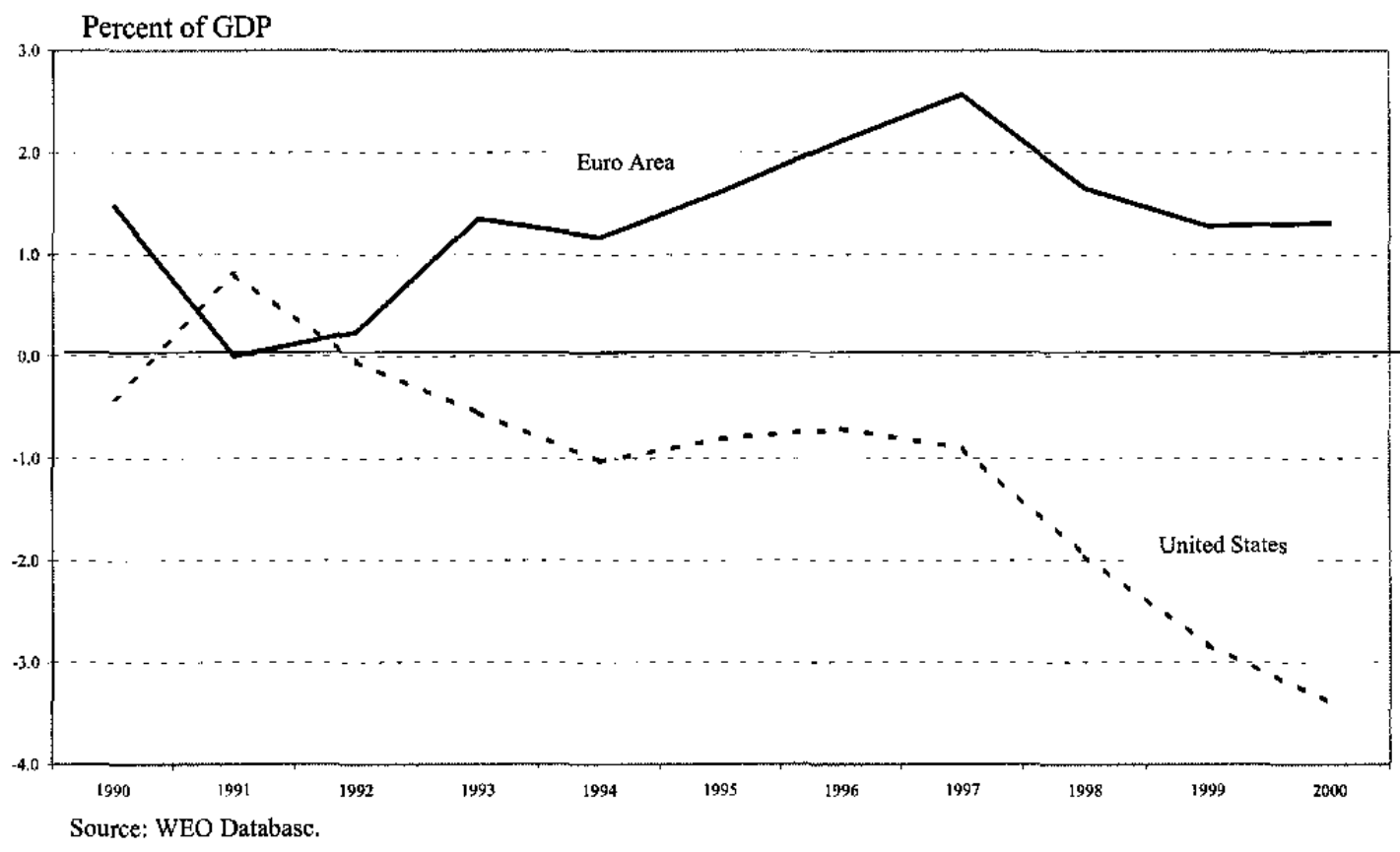

Figure 6. Productivity Growth and Changes in the Euro

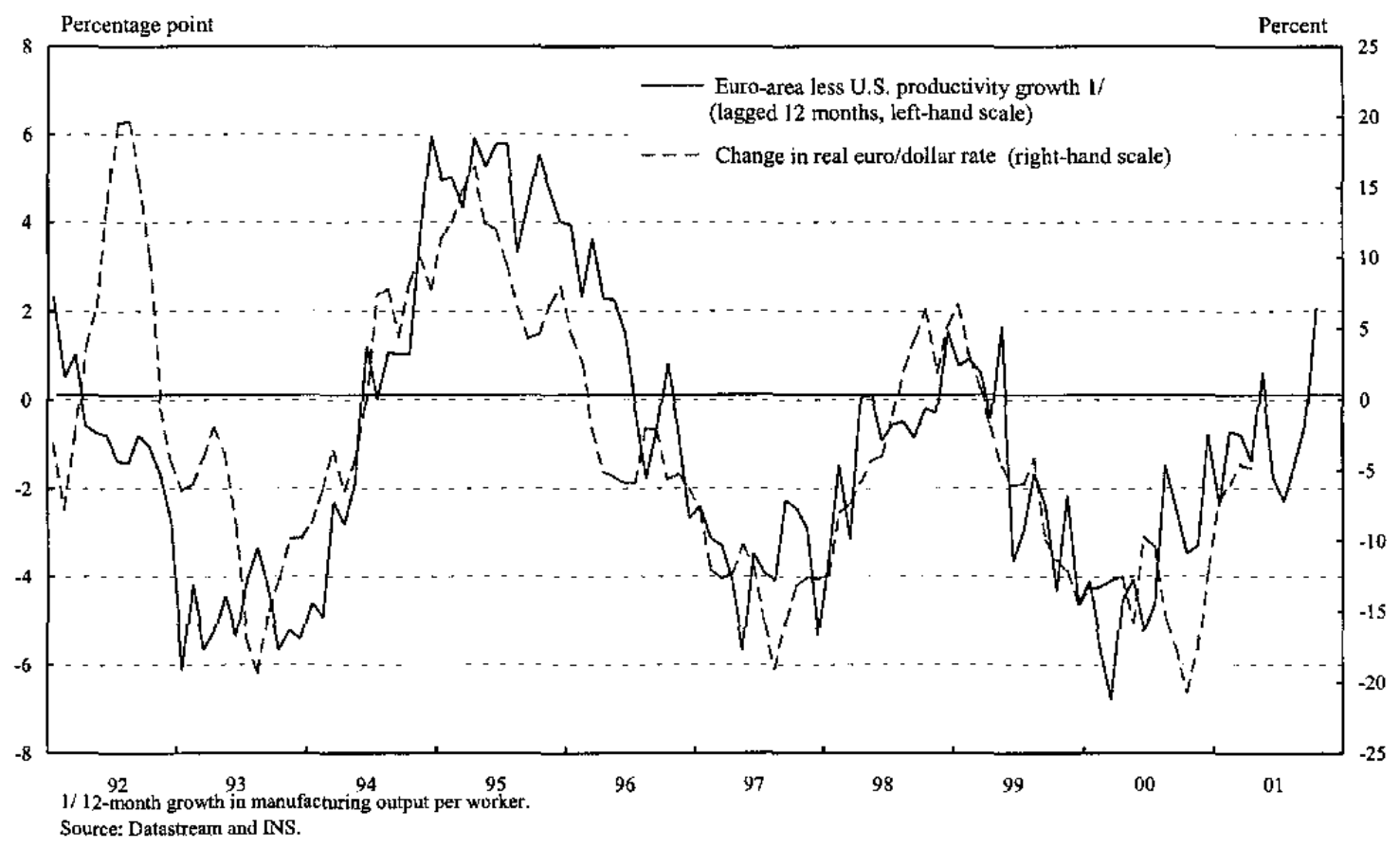


Starting from the mid-1990s, this would cumulate to about 5 percent by the end of the decade, compared with the actual depreciation of the euro against the dollar of 34 percent.

More fundamentally, the associated exchange rate appreciation would not undermine U.S. competitiveness. But the U.S. current account deficit has ballooned since the mid-1990s, and in a way that has been consistent with traditional trade relationships. Equilibrium estimates also suggest that the dollar has become highly overvalued. Finally, the BalassaSamuelson story runs contrary to developments in real interest rates. Ongoing, expected real exchange rate appreciation should lower the real interest rate in the appreciating country in a world of high capital mobility. ${ }^{18}$ Yet U.S. long-term interest rates rose substantially relative to euro-area rates over this period.

\section{F. Portfolio Shifts}

The introduction of the euro caused widespread changes in capital markets in the region (Galati and Tsatsaronis (2001)). Among these was the lowering of barriers to crossborder financial transactions, creating more liquid markets in euro-denominated debt securities than existed for the legacy currencies. One result was an explosion in the issuance of euro-denominated corporate bonds by issuers residing both within and outside the euro area. On the investor side, institutions within the euro area naturally switched to investments in euro assets from those in the legacy currencies. But the switch may not have been one-forone, at least ex ante. Securities that were previously considered foreign assets in portfoliosbecause they were denominated in other legacy currencies - would be considered domesticcurrency assets under the single currency. With unchanged portfolio guidelines on the allocation between domestic- and foreign-currency assets, funds would be "freed up" for investment in other currencies, such as dollars. In addition, there were changes to portfolio guidelines for some euro-area institutions (such as French pension funds) that allowed increases in the share allocated to foreign-currency assets. Finally, foreign investors have shown limited interest in acquiring euro-denominated assets, in contrast to the appetite of borrowers have in issuing them.

In the conceptual framework, these portfolio shifts would affect the exchange rate via changes in the expected excess yield on euro-denominated assets. Specifically, increased demand for borrowing in euros relative to the supply of investors' funds would raise the excess yield and depress the value of the euro. So the anecdotal evidence on capital market behavior is consistent, in principle, with the depreciation of the euro on a multilateral basis that coincided with its introduction. This story is pursued in more detail in Section VI, including an illustration of the impact of an assumed change in the excess yield on the exchange rate.

\footnotetext{
${ }^{18}$ This is in fact what has been observed in Japan (Meredith (1998)).
} 


\section{G. Nonfundamental Market Dynamics}

De Grauwe (2000) explains the weakness of the euro since 1999 in terms of how markets form views about the factors driving exchange rates. Given great uncertainty about equilibrium levels of exchange rates, short-run movements tend to be driven by technical and chartist analysis. Sustained movements in one direction or another then lead to a search for fundamentals that explain these developments. Analysts selectively assess the evidence to find the appropriate fundamentals, leading to a self-reinforcing process. In the case of the euro, this led to an excessive focus on favorable aspects of the U.S. economy, even though such a view was not supported by observable news about the fundamentals taken as a whole.

This story is consistent with much other research on market dynamics that appears at odds with conventional views of rationality. Past experience (e.g., the dollar in the early 1980 s and the yen in 1995) also suggests that markets can accentuate exchange rate movements through extrapolating recent developments in the absence of well-formed views of the fundamentals. The general premise is hard to dispute, given that there is no way of testing it directly-instead, it serves a role as a "residual" explanation when all other identifiable factors have been exhausted. As discussed below, there are more fundamental reasons that may explain much of the depreciation of the euro against the dollar, leaving nonfundamental market dynamics as, at best, a supporting factor. But their relative importance may well become primary in the latter stages of currency cycles. The persistent weakness of the euro through mid-2001, in spite of a partial reversal of the equity-market based explanation for its weakness, could be consistent with this phenomenon.

\section{EQUity MARKETS AND THE EURo/Dollar RATE}

As discussed above, macroeconomic developments since the mid-1990s point to the presence of positive demand and supply shocks in the U.S. economy relative to the euro area. What factors could explain such these shocks, and what proportion of the change in the euro/dollar rate could they explain? The explanation pursued here is the surge in U.S. equity prices since the mid-1990s, which raised market capitalization relative to GDP to unprecedented levels. Higher equity prices would boost both consumption and investment, explaining a shock on the demand side; higher investment would also raise the capital stock and thus labor productivity, increasing potential output on the supply side. ${ }^{19}$

${ }^{19}$ Sinn and Westermann (2001) question the role of equity prices in explaining exchange rate movements from a portfolio balance perspective. The channels advanced here, however, are not based on portfolio effects, but rather the impact of equity price movements on aggregate spending and thus on interest differentials. Indeed, assets in different currencies are assumed to be perfect substitutes in the model. 
An immediate objection to this story is that the equity price surge in the late $1990 \mathrm{~s}$ was not confined to U.S. markets. Prices rose in all developed markets: why would this lead to a disproportionate shock to the U.S. economy? There are three reasons for such an effect. The first is the huge rise in prices in new-economy companies, which are more important in the U.S. than other economies. As a result, broad measures of equity prices that include these share rose by more in U.S. markets (Figure 7). The second is that equity market capitalization in general is much larger relative to GDP in the U.S. than in most overseas economies, with the notable exception of the United Kingdom. U.S. market capitalization rose from about 80 percent of GDP in 1994 to 180 percent in 1999, an increase of 21/4 times (Figure 8). Capitalization of euro-area markets rose from about 30 percent of GDP to 90 percent over this period, rising 3 times. Thus, while the proportional rise in euro-area capitalization was larger, the increase as a share of GDP was 40 percent smaller than in the U.S. (Figure 9). The third explanation is that typical estimates find a higher propensity to consume out of equity market wealth for U.S. households than those in most other countries. ${ }^{20}$ A given increase in equity wealth relative to GDP would then result in a larger demand shock in the U.S. than elsewhere.

To assess the empirical importance of equity prices for exchange rates, equity market shocks were introduced into a two-region model that captures some key features of the U.S. and other industrialized economies. The model is described in Annex A; here we summarize the aspects relevant to the simulations. The two regions are generally identical, with the following exceptions. The first is that the ROW is twice the size of the U.S., broadly consistent with relative shares in developed countries' GDP. Second, the U.S. has a lower leverage ratio, defined as the share of business-sector financing represented by debt versus equity. Specifically, both equity and debt in the baseline data are 80 percent of U.S. GDP, consistent with a capital/output ratio of 1.6. In the ROW region, the ratios are 30 percent and 130 percent respectively. Thirdly, U.S. households are assumed to have a higher discount rate on future labor income, which implies a higher propensity to consume out of financial wealth. In particular, the propensity to consume out of financial wealth for U.S. households is 0.05 , while that for ROW households is 0.03 . The exchange rate between the two regions is determined by uncovered interest parity, and thus reflects both the current and all expected future interest rate differentials.

To understand the simulations, it is useful to first describe the relationships that determine equity valuations. Equity prices reflect the discounted value of future profits accruing to equity holders. The model incorporates forward-looking behavior, as expected

${ }^{20}$ See Edison and Sløk (2001a). Theoretically, this phenomenon would be consistent with non-U.S. households having a lower discount rate on future labor income. Changes in financial wealth would then represent a smaller proportion of overall household wealth, implying a correspondingly smaller marginal propensity to consume out of wealth. More prosaically, U.S. equities could tend to be held directly by households, while in Europe equities may tend to be held more in trusts, pension funds, and indirectly through other financial intermediaries. 
Figure 7. Equity Price Indexes

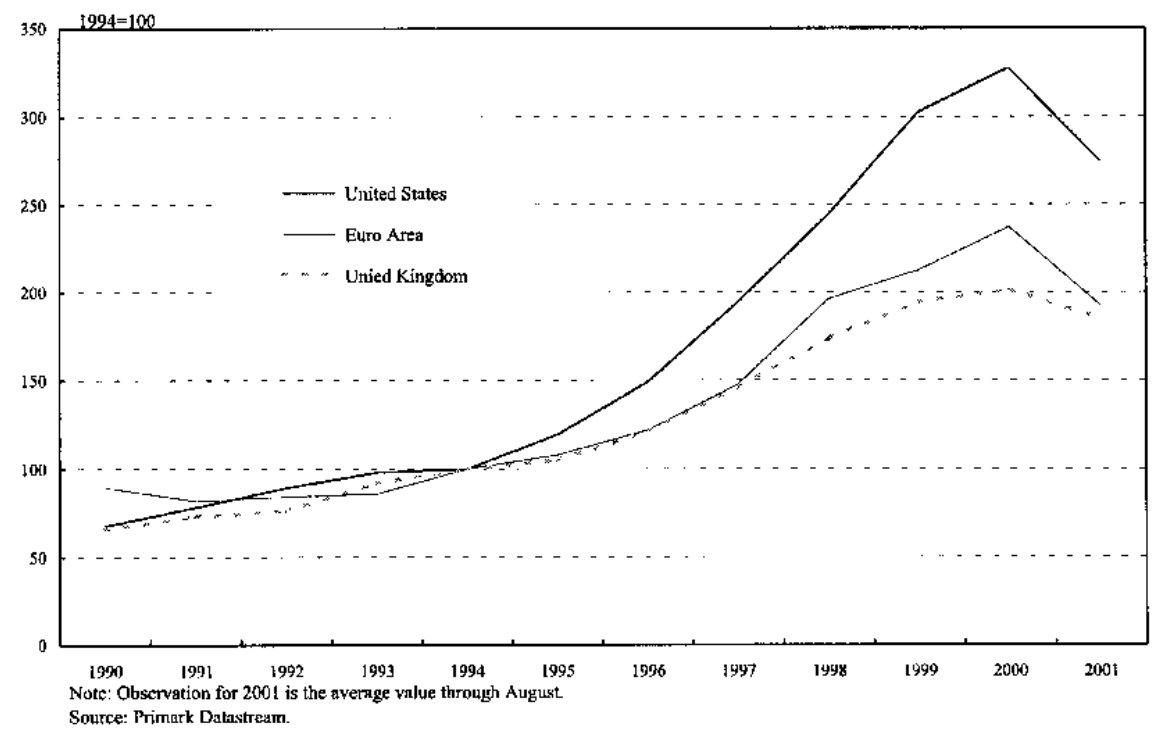

Figure 8. Equity Market Capitalization Ratios

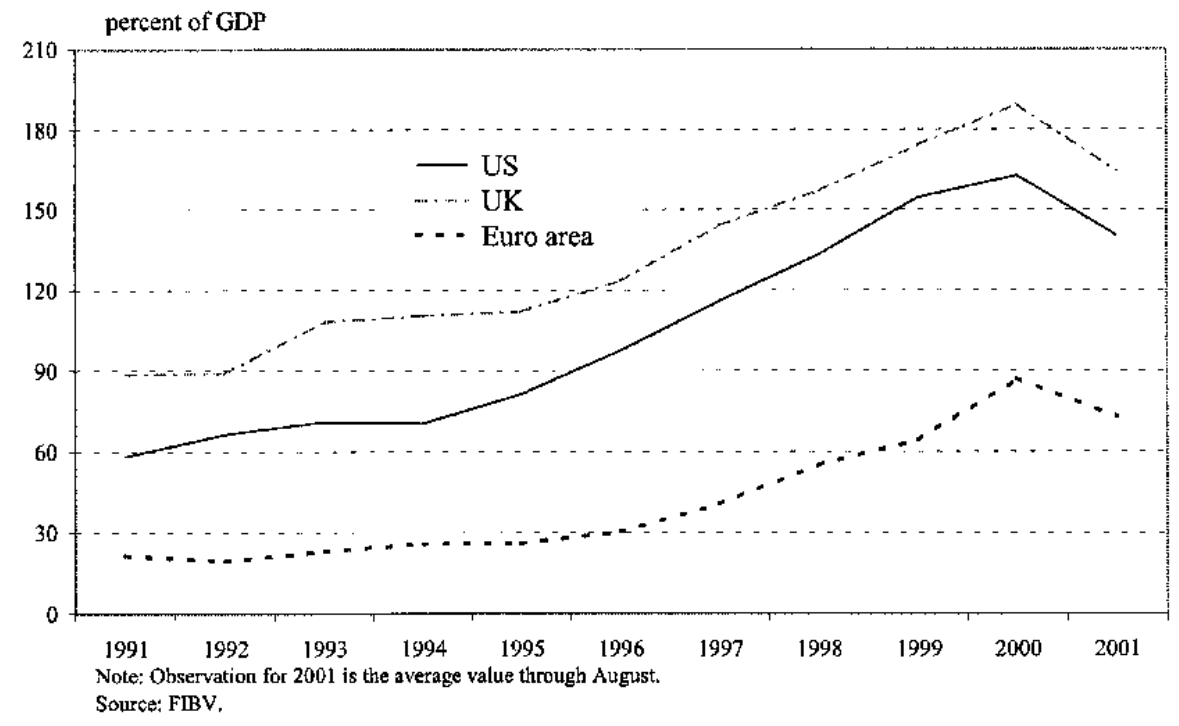

\section{Figure 9. Differences in Equity Market Capitalization Ratios}

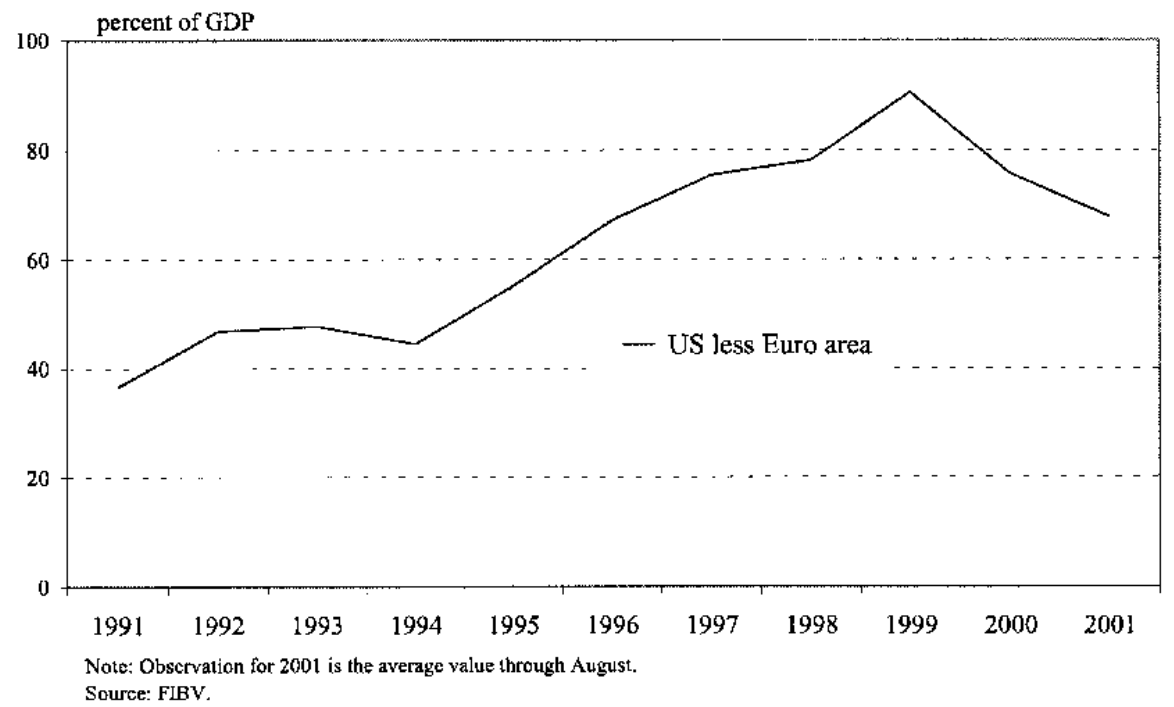


profits are based on the model's projections for the relevant variables. Current profits per share are given by (the mnemonics are described in Annex A):

$$
\pi=\left\{\alpha(Y *(P / P C)-T)-\delta K_{-1}-r^{b} B D_{-1}\right\} / S
$$

and the present value of the discounted profit stream by:

$$
P Q=\left(\pi+P Q_{+1}^{e}\right) /(1+r+\rho)
$$

Repeatedly substituting out for the expected future share price in equation (7) implies that the current price can also be expressed as the discounted value of current and expected future profits. In the form in which equation (7) is actually written, expected future profit growth is embodied in the future value of $P Q$ on the right-hand side. The discount rate is the sum of the risk-free real interest rate and an "equity premium" $(\rho)$, with the latter defined as the excess rate at which investors discount future equity returns.

The nature of the equity premium is a source of controversy. Mehra and Prescott (1985) showed that the historical equity premium is much too large to be associated with compensation for risk in conventional consumption asset pricing models. As yet, however, a convincing alternative has not been advanced. Possible explanations for the historical size of the premium fall into two broad categories: those that are consistent with market efficiency, and those that are not. Examples of the former include utility-of-wealth functions with properties more exotic than those conventionally posited, or transactions costs unique to equity investing. The latter category includes misperceptions of the true risks of equity investing, or of future profit growth.

Several factors could have caused a decline in the equity premium in recent years. Transactions costs have fallen dramatically with the advent of internet brokers, while the development of low-load, index-linked mutual funds has allowed risk diversification at minimal expense. More abstractly, the end of the Cold War is sometimes mentioned as having diminished the risk of equity investing. In terms of market efficiency, the fact that equity returns have exceeded those on other assets has become increasingly recognized in light of popular discussion (e.g., Siegel (1994)). It also seems plausible that investor psychology has played a role (Shiller (2000)). To the extent that the above factors led to an initial decline in the equity premium, investors realized capital gains on existing assets, reinforcing the perception that equities yielded excess returns. Confusion about appropriate valuations was further heightened by the view that the new economy invalidated traditional approaches to equity pricing. The presence of such a bubble is clear for technology stocks, which have already corrected dramatically. For stocks in traditional sectors, the situation is less obvious, and depends on the assumptions one makes about the equilibrium shift in the equity premium.

For the purpose of this analysis of past developments, explaining the equity premium is not of central importance. The premium itself does not appear in the model except in the 
equity valuation formula, and changes in it affect prices in a way that could arise from a variety of sources. A forward-looking assessment, in contrast, would clearly require a judgment as to the plausibility of the expectations that underlie equity valuations, and thus how equity prices might evolve in the future.

Looking back, the more germane issue is how large the shock would have to be in order to explain the surge in valuations in the second half of the 1990s. To assess this, a shock to the equity premium was phased in for both the U.S. and ROW regions during 1995-2000 that generated profiles for market capitalization to GDP ratios similar to those in Figure $8 .^{21}$ Not surprisingly, these shocks had to be large to generate suitable changes in equity valuations. This is especially true because the direct impact on equity prices of a lower premium is partially offset by two factors. The first is higher risk-free interest rates caused by the boost to aggregate demand when equity prices rise. The second is lower future profit growth (per share) that results from the capital deepening associated with higher investment. ${ }^{22}$ In the event, it was necessary to reduce the premia in both the U.S. and the euro area from baseline values of slightly over 5 percentage points to negative 4 percentage points by 2000 , implying a total swing of 9 percentage points (Figure 10). ${ }^{23}$

The effects of this shock on relative market capitalization and the bilateral exchange rate are shown in Figure 11. The "capitalization gap" between the U.S. and the ROW regions rises from 50 percent of GDP in 1994 to 90 percent in 2000, while the dollar appreciates by 23 percent over the same period. This compares with the 29 percent appreciation in the dollar's real effective value from 1994 to 2000 . The exchange rate moves at the same time as equity valuations change, as all of the future effects of valuation changes are incorporated in the spot exchange rate under rational expectations. This differs from the actual experience, where the exchange rate lagged somewhat the equity valuation changes. This could reflect delays that are not incorporated in the model in recognizing the appreciating the impact of such changes on activity, real interest rates, and currency values.

Other aspects of the simulation are consistent with the stylized facts since the mid1990s. For instance, the U.S. output gap rises, and actual output increases by even more given the boost to potential from a higher capital stock (Figure 12). Yet the U.S. inflation rate

${ }^{21}$ Beyond 2000, the shocks were calculated to keep the ratios of equity market capitalization to GDP constant at their new, higher, levels.

${ }^{22}$ This effect is discussed by Summers (1981) in the context of U.S. corporate taxation. He observes that equity values will rise by more when taxes fall if investors do not foresee the effects of capital accumulation on the marginal productivity of capital.

${ }^{23}$ The baseline value is similar to the 6.1 percent figure estimated for the U.S. by Mehra and Prescott for 1889-1978. Epaulard and Pommeret (2001) estimate premia ranging from 1.5 to 6.5 percent for France, judging the higher figure to be more representative. 


\section{Figure 10. Simulated Equity Premia}

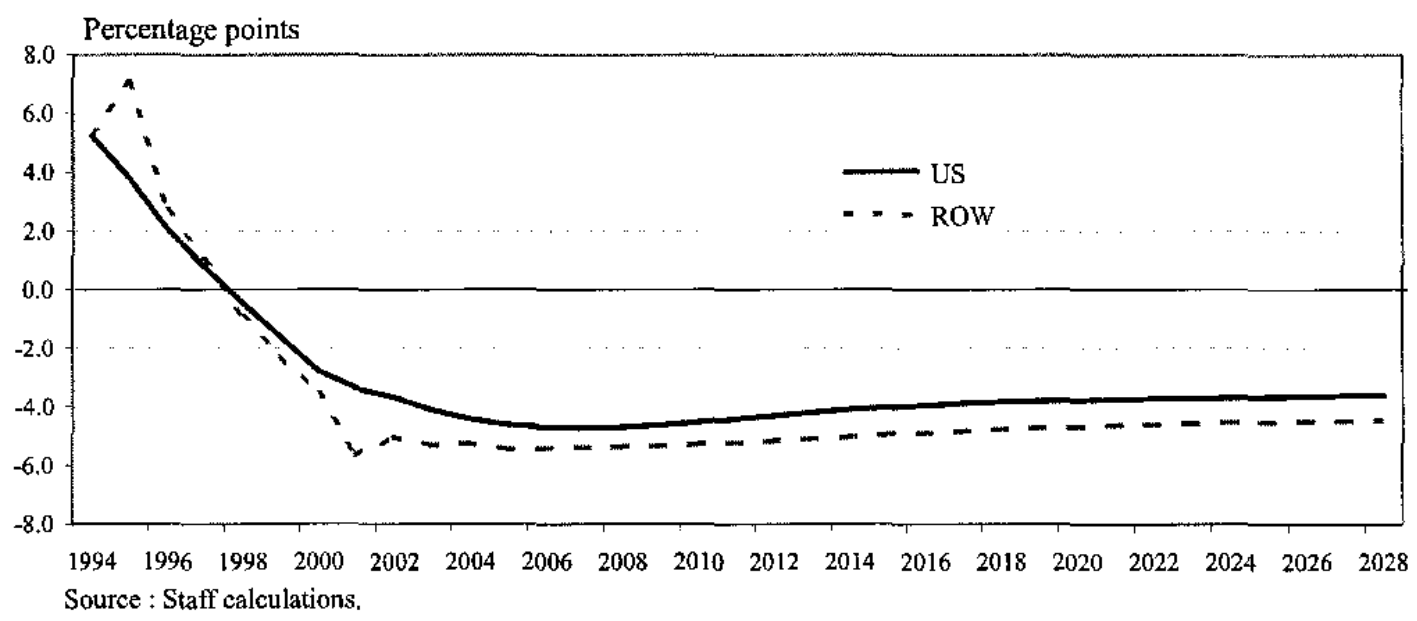

Figure 11. Simulated Market Capitalization and Exchange Rate

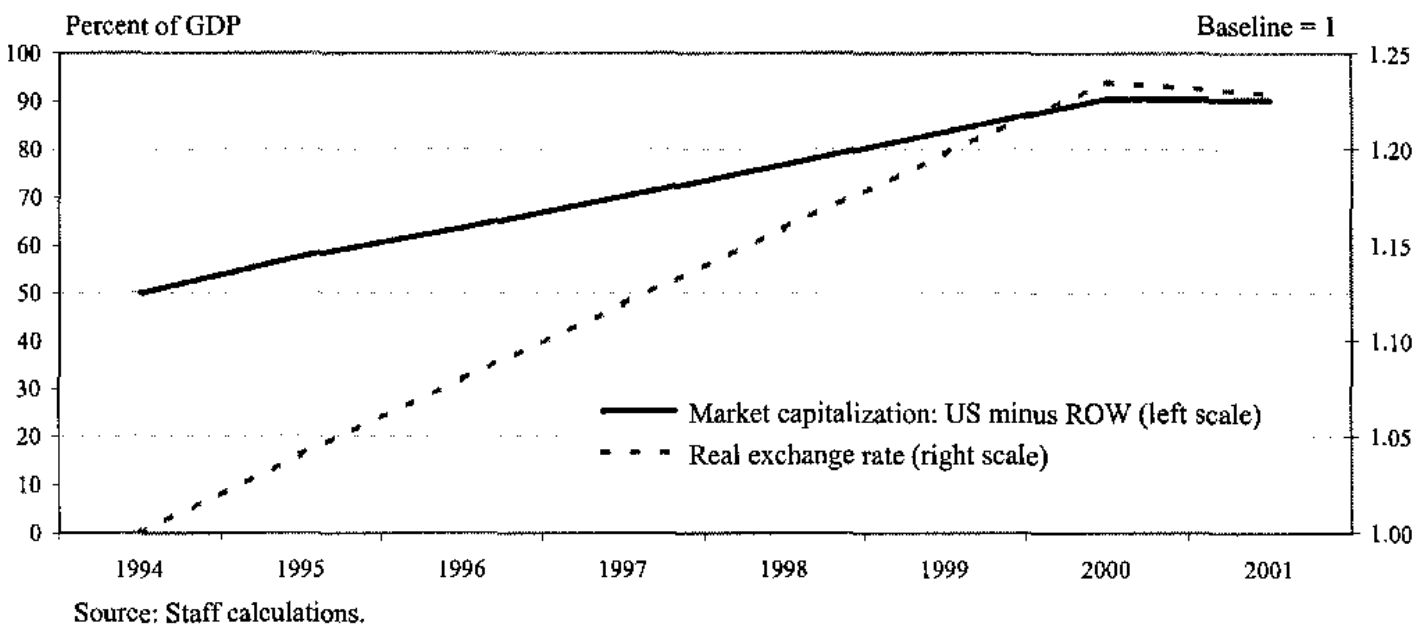


Figure 12. Simulated Output and Output Gaps

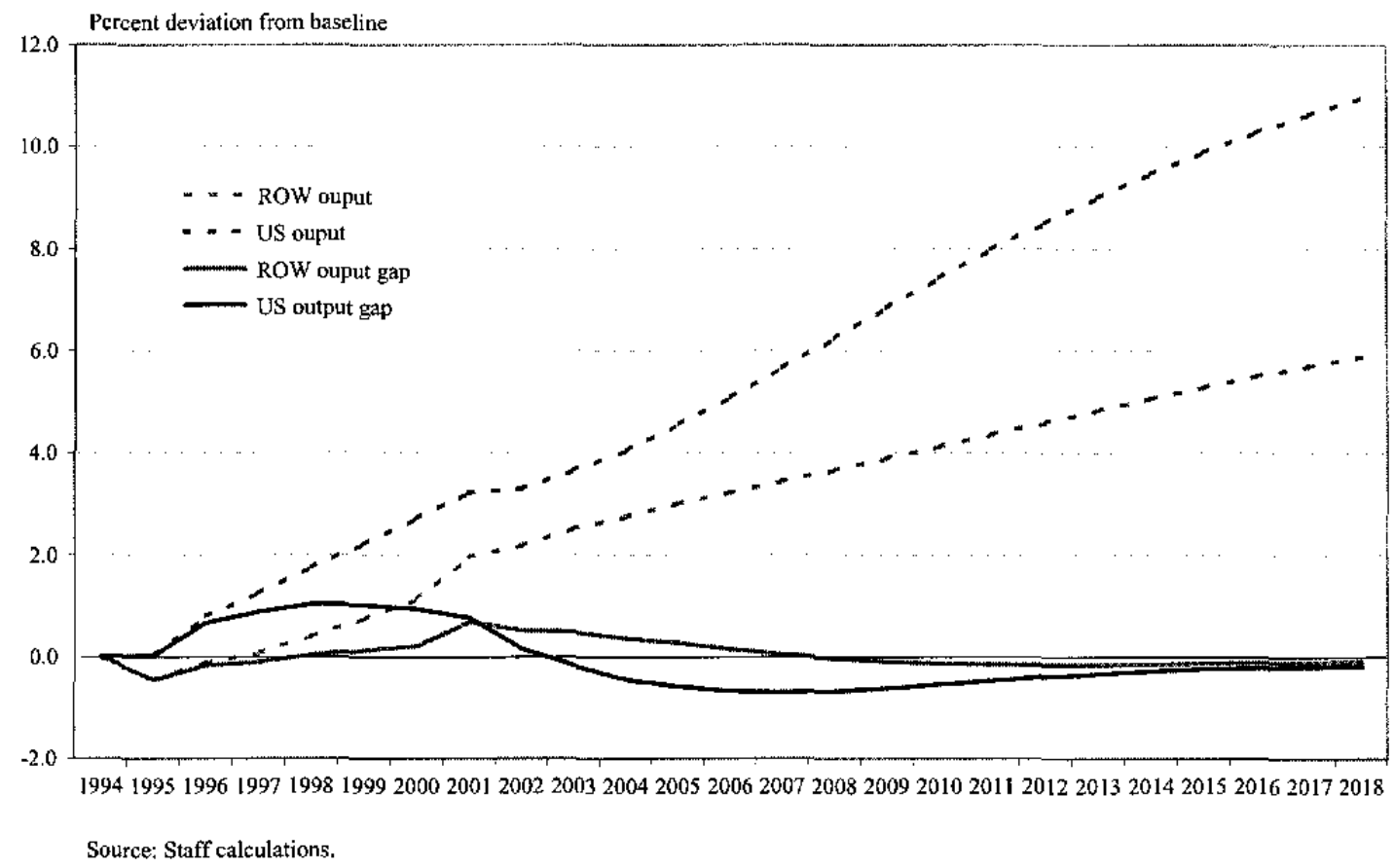

Figure 13. Simulated Trend Labor Productivity Growth

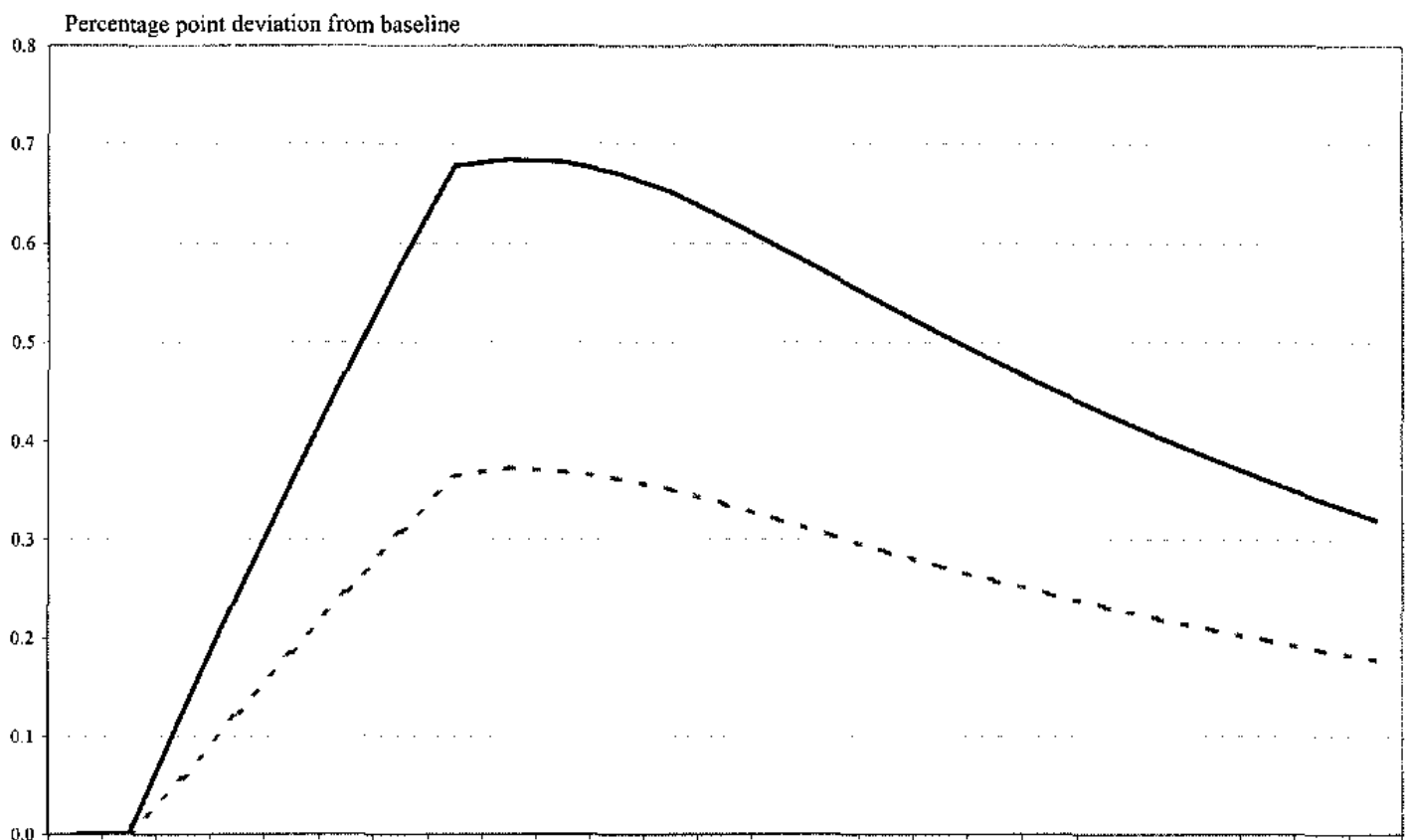

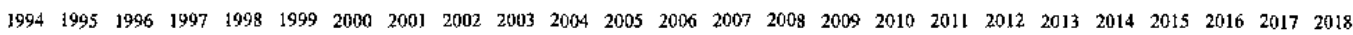
Source: Staff calculations. 
is actually pushed down for several years, as higher labor productivity growth temporarily reduces growth in unit labor costs, and the strong dollar pushes down import prices (Figures 13 and 14). ${ }^{24}$ The trade deficit widens by $2 \frac{1 / 2}{2}$ percent of GDP from 1994 to 2000 , reflecting both the surge in domestic demand and the effects of a higher exchange rate on competitiveness, while the ROW records a surplus (Figure 15). For the ROW region, the shock is initially (slightly) contractionary, although capital accumulation pushes up both potential and actual output later in the decade. Inflation is slower to fall than in the U.S., however, because of the effects of the weaker exchange rate on import prices.

Short-term real interest rates in the U.S. do not begin to rise above their baseline values until late in the decade, as the impact of higher output and lower inflation on monetary policy are roughly offsetting (Figure 16). Long-term real interest rate move up sooner, however, reflecting the anticipated future impact of the positive demand shock. In the ROW region, the interest rate response is more muted, as the effects on activity are smaller. The differential between long-term real interest rates in the two regions rises from the baseline value of zero to almost 1 percentage point by 2000 - a movement that, again, is consistent with the evidence.

Assuming that equity valuations stabilize relative to GDP at the levels observed in 2000 , the exchange rate would peak in 2000 and gradually decline thereafter (Figure 17). The pace of decline is determined by the interest rate differential between the U.S. and the ROW; as this differential peaks at about 1 percentage point, the decline is very gradual. The exchange rate does not fall back to its initial level until 2040, after which it gradually asymptotes to a level that is about 8 percent below baseline. This long-run depreciation reflects the fact that the U.S. output rises relative to ROW output given greater capital accumulation. As the two outputs are imperfect substitutes in global consumption, this requires a decline in the relative price of U.S. output to equilibrate world product markets.

The long-run paths of the other variables are, for the most part, not surprising. One notable feature, however, is the powerful effect on U.S. inflation and unemployment of the eventual tapering off of the favorable shock to the equity premium. Even if the shock does not reverse, its stabilization leads to a significant rise in U.S. inflation during 2001-2005. The reason is that exchange rate appreciation is no longer dampening import prices. At the same time, wage growth is relatively high, as wages are set against the background of the favorable productivity trends of the late 1990 s and an unemployment rate that is initially below its long-term equilibrium level.

These effects, of course, depend on the model and its parameterization. Larger or smaller exchange rate movements can be obtained with alternative choices. In this respect, an

${ }^{24}$ The simulated rise in U.S. labor productivity growth of about $1 / 2$ percentage point per year is similar to Nordhaus' (2001) estimate an acceleration in U.S. productivity (outside the technology sector) of 0.54 percentage points during 1995-98. 
Figure 14. Simulated Inflation Rates

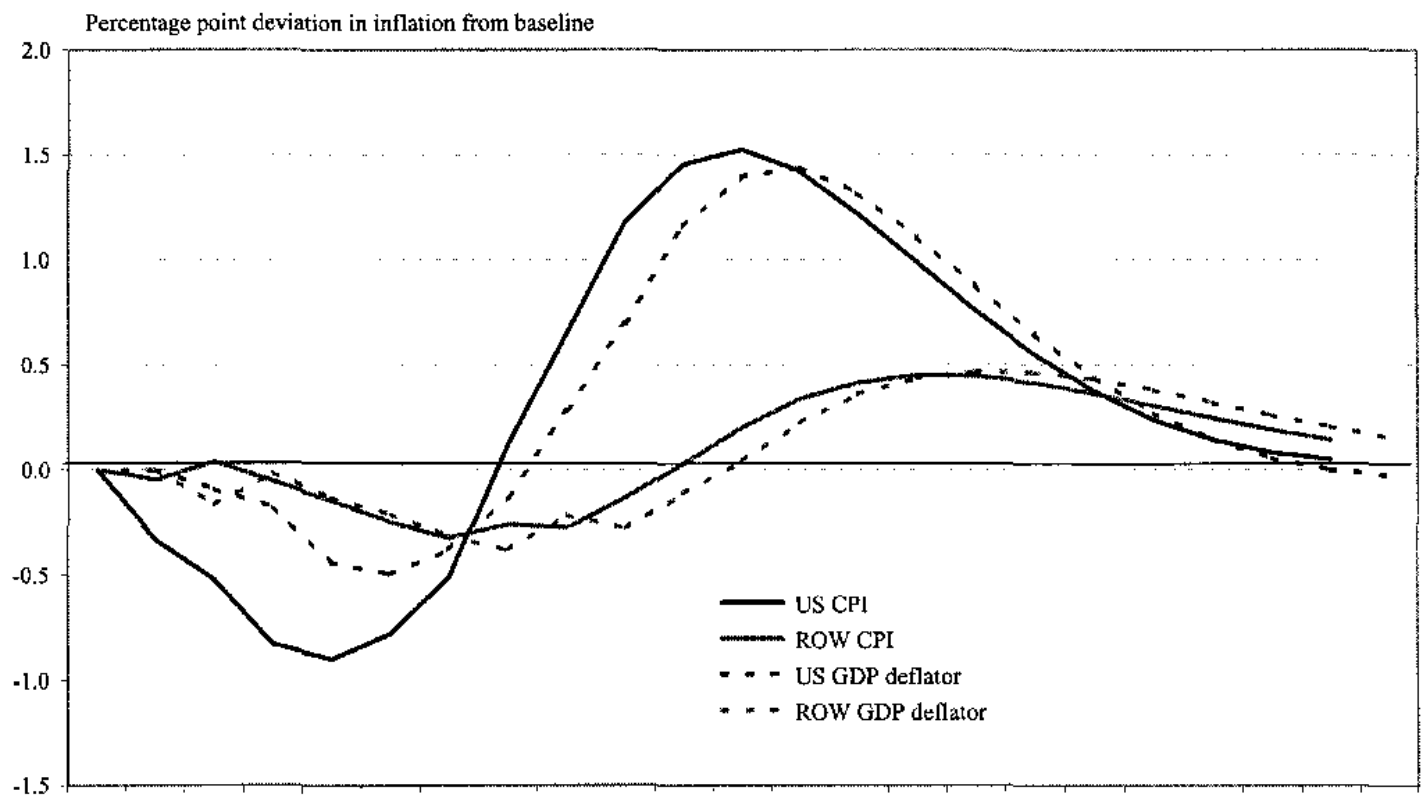

1994199519961997199819992000200120022003200420052006200720082009201020112012201320142015

Source: Staff calculations.

Figure 15. Simulated Trade Balances

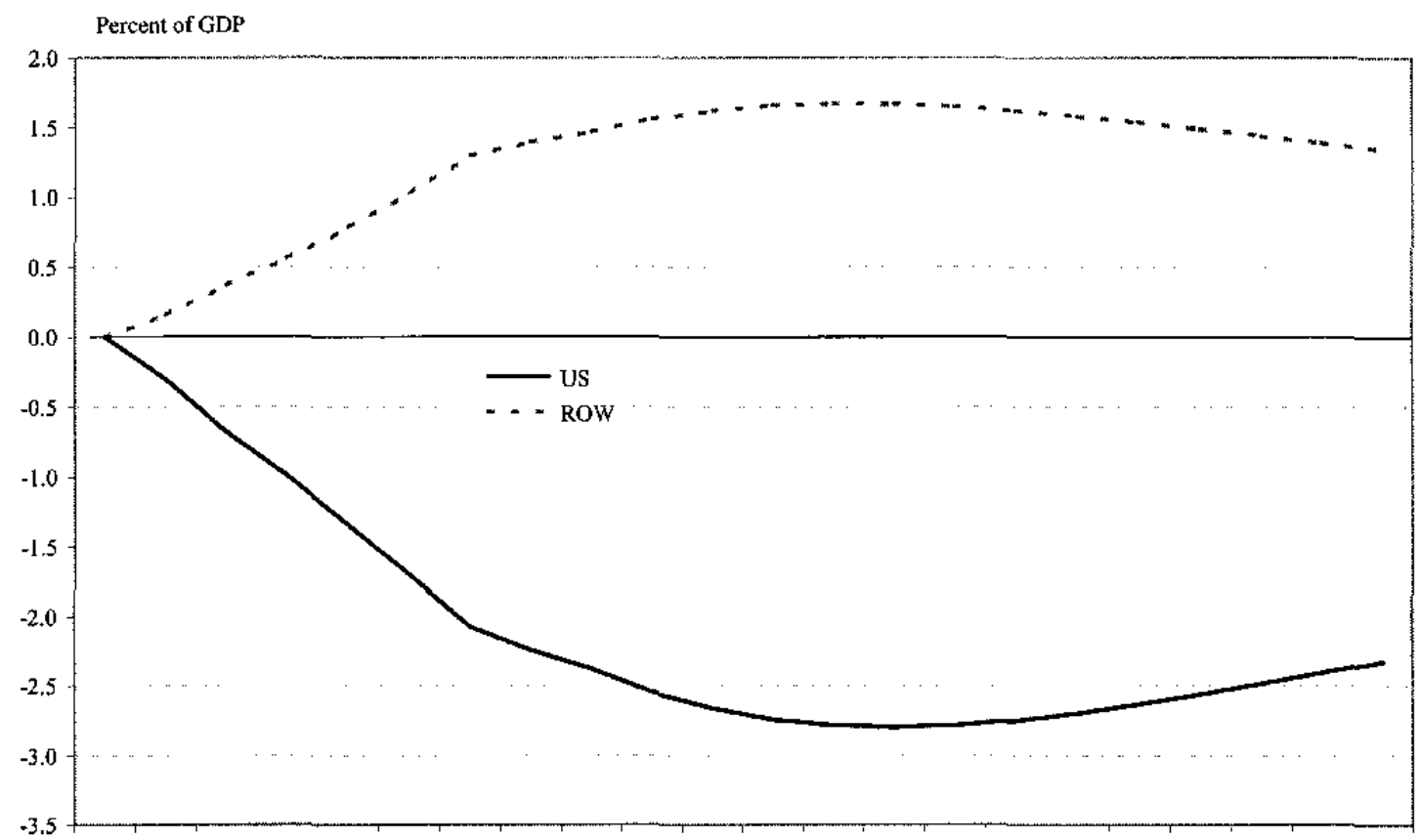

1994199519961997199819992000200120022003200420052006200720082009201020112012201320142015 Source: Staff calculations. 
Figure 16. Simulated Real Interest Rates

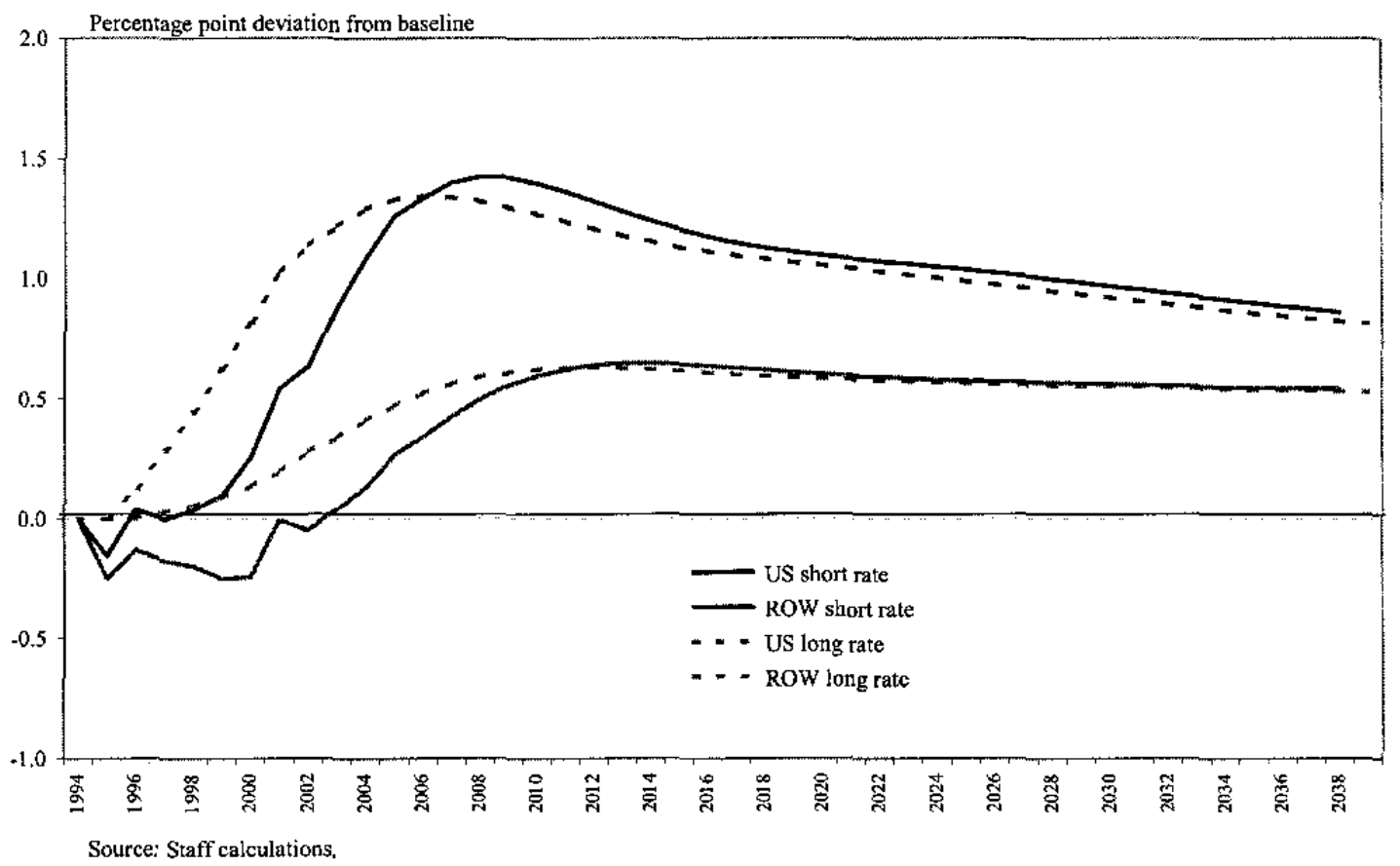

Figure 17. Simulated Market Capitalization and Exchange Rate: Permanent

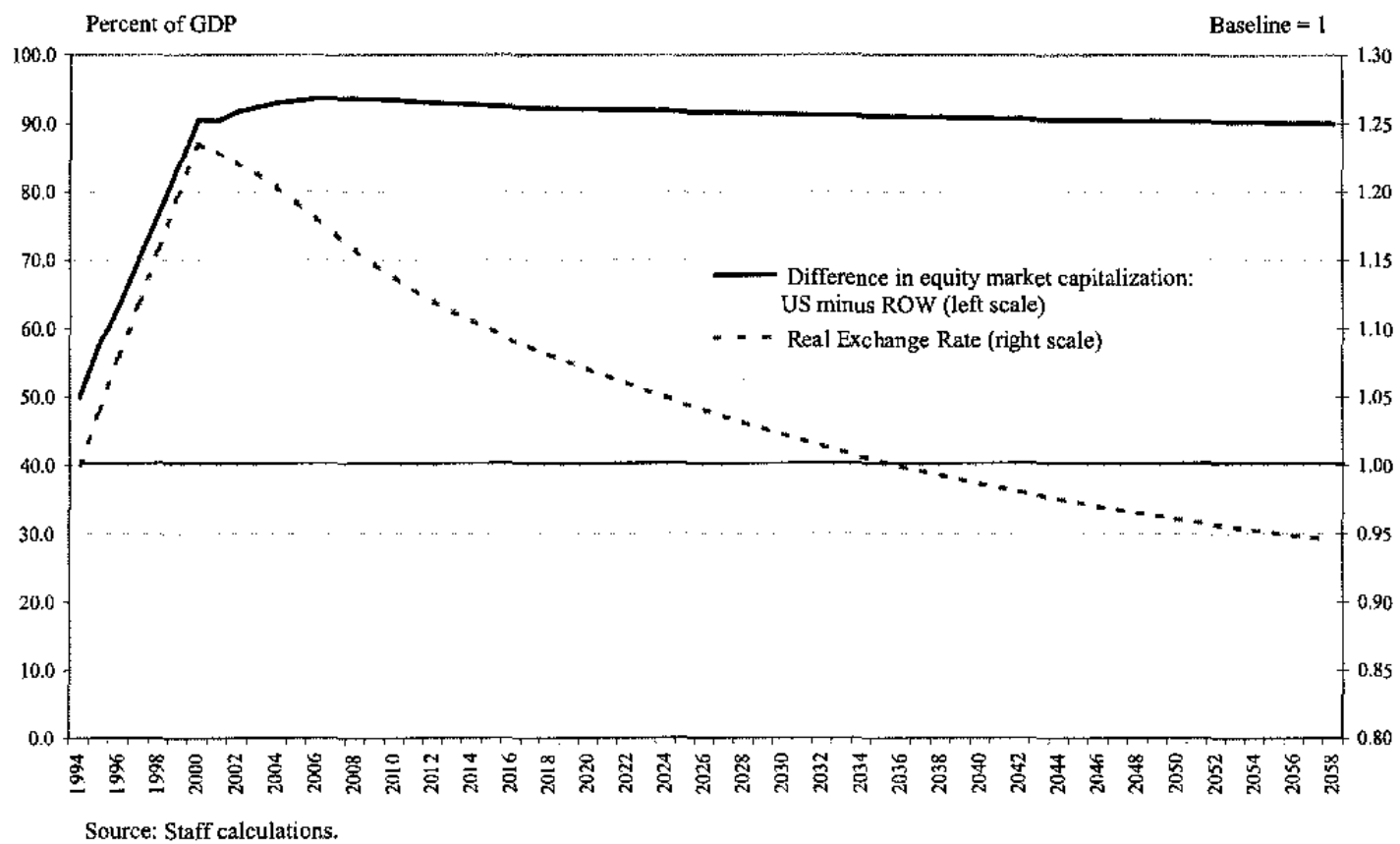


important property of the model is the interest-sensitivity of aggregate demand, which depends both on the intertemporal elasticity of substitution of consumption and the elasticity of substitution between factors in production. The less interest sensitive is aggregate demand, the more interest rates must rise in the simulations to "crowd out" the increase in spending induced by higher equity prices. Larger interest-rate changes generally lead to larger exchange rate changes, given that the exchange rate is driven by interest differentials. As discussed in the Appendix, model parameters were chosen to make demand relatively interest-rate elastic, thus preventing an implausibly large rise in real interest rates. Using alternative parameters that implied lower interest elasticities generated exchange rate movements in the range of 40 percent. ${ }^{25}$ Working in the other direction, the results also depend on the assumption that the propensity to consume out of equity wealth in the U.S. is higher than that in the ROW. Setting these propensities to be the same resulted in a smaller exchange rate change of about 12 percent. The result in the baseline simulation of a 23 percent exchange rate change was typical of the middle range of effects obtained from several simulations with alternative parameter values.

The model can be used to assess an alternative explanation for the rise in equity values and the dollar, specifically that they reflect an acceleration in underlying U.S. productivity growth. Rather than lowering the equity premium, productivity growth was raised in both regions, but with a larger increase in the U.S. For illustrative purposes, trend productivity growth was raised by $1 \frac{1}{2}$ percentage points during $1995-2000$ in the U.S., and by half that in the ROW. The results do not support a productivity-based story. In fact, higher productivity growth depresses, not raises, relative equity capitalization in the U.S. and the value of the dollar (Figure 18). The latter occurs because, in spite of a rise in the long-term real interest differential, more rapid expansion in U.S. output requires an ongoing decline in the real exchange rate.

The depressing effects of higher productivity growth on equity values may seem counter-intuitive. Higher productivity growth is often thought of as leading to higher profit growth, which would be discounted into higher equity prices. This effect does not hold in the simulation for two reasons. First, higher productivity boosts profit growth, but not profit growth per share. This is because higher output growth is associated with a faster rate of capital accumulation. Capital must be financed, and this requires issuing new shares or raising new debt. Either approach incurs costs to existing shareholders-owners of existing capital do not benefit from growth that is not accompanied by a rise in discounted profits per unit of capital. Secondly, discounted profits are pushed down because higher productivity growth requires a higher real interest rate. Investment needs to rise to maintain the same capital-to-output ratio when productivity growth increases; consumption also tends to rise, as

${ }^{25}$ The intertemporal elasticity of substitution in consumption was changed to $1 / 4$ from its baseline value of 1 , while the production elasticity was changed to $1 / 2$ from 1 . With these values, the real short-term interest rate in the U.S. rises by 3 percentage points above baseline by 2000 , as opposed to slightly over $1 / 2$ percentage point in the base-case scenario. 
Figure 18. Market Capitalization and Exchange Rate: Productivity Shock

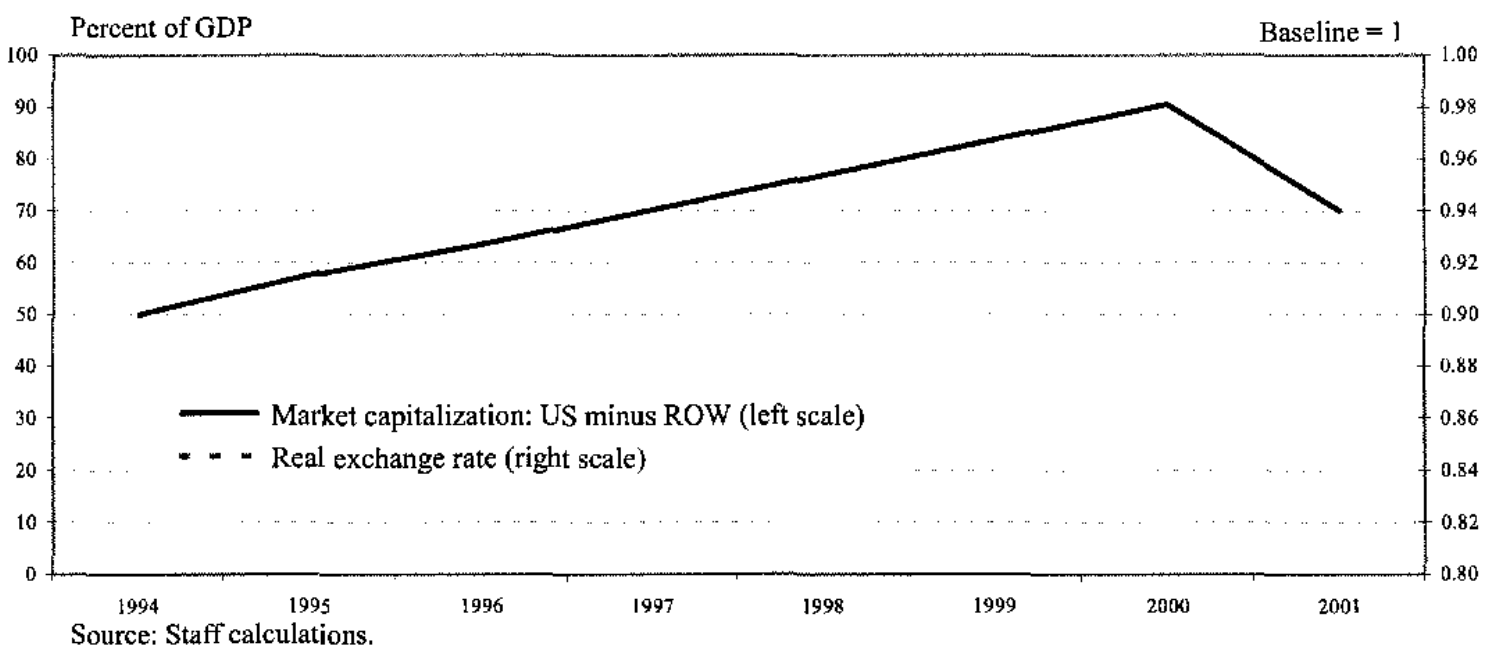

Figure 19. Simulated Market Capitalization and Exchange Rate:

Zero Equity Premium in 2001

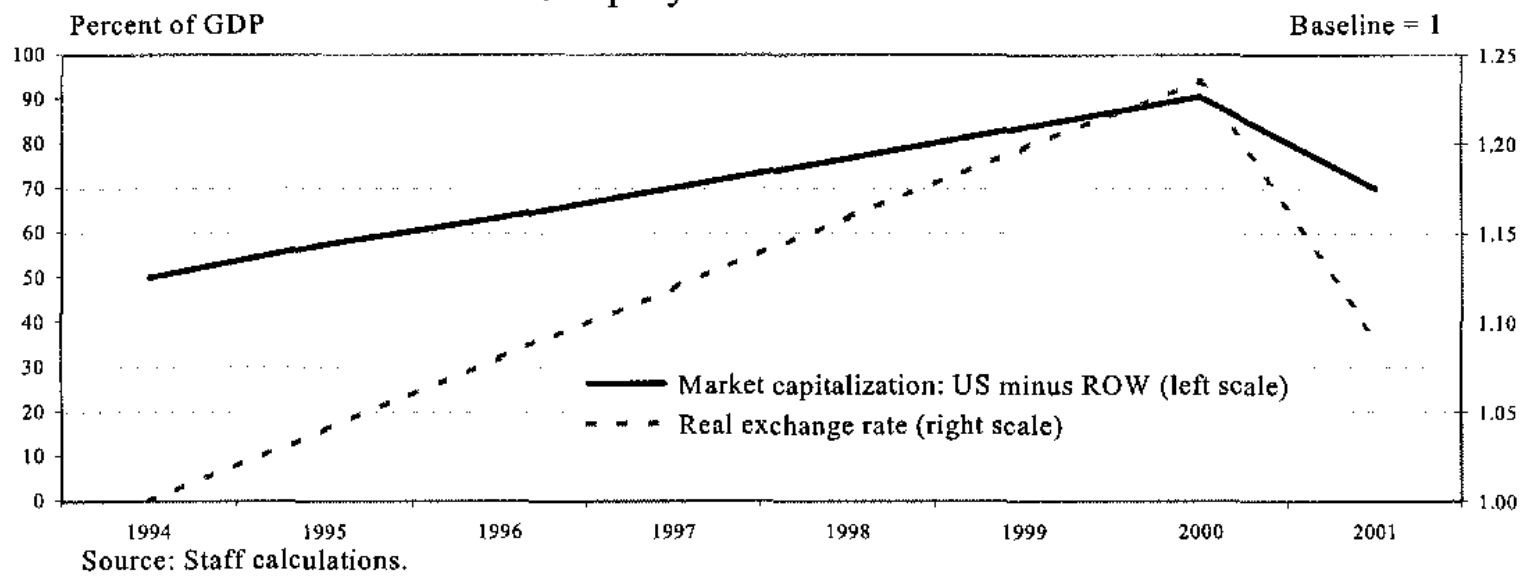


future labor income is higher. Thus higher productivity growth leads, ex ante, to excess aggregate demand. The real interest rate must increase to equilibrate demand and supply. ${ }^{26}$

Offsetting these factors, higher productivity growth can raise equity prices by increasing rents accruing to existing capital when there are adjustment costs to putting in place new capital. These adjustment costs are reflected in the parameters on Tobin's $q$ and on potential output growth in the investment equation; higher adjustment costs imply lower parameters. To test the sensitivity of the results to alternative values, the parameter on Tobin's $q$ was cut in half and that on potential output growth was set to zero. Under these assumptions, the simulations show a small rise in equity values as productivity accelerates. Yet the effect on aggregate demand is too small to outweigh the depreciation due to an expanding relative supply of U.S. output, and the dollar still depreciates on impact. A pure productivity growth story, then, does not work as an explanation for dollar appreciation in this model. ${ }^{27}$

The paths for equity valuations and the exchange rate in the baseline scenario assume that equity premia in both the U.S. and ROW stabilize at negative values in the long run. While there may be sound reasons for a substantial decline in premia from historical levels, or even their elimination, it is harder to rationalize persistently negative values. The fact that negative premia are required to raise equity prices to observed levels in 2000 suggests an element of over-valuation in prices-although the subsequent correction would have narrowed it. To abstract from possible over-valuation, an alternative scenario was performed where both equity premia were assumed to return to zero starting in $2001-5$ percentage points below their initial value, but 4 above their long-run levels in the baseline scenario.

In this case, the equity capitalization gap between the two regions drops to about 75 percent of GDP in 2001 from 90 percent in 2000 (Figure 19). This is similar to the observed gap in the first half of 2001 following the correction in global prices. The drop in the exchange rate is more pronounced, as it declines to about 10 percent above baseline. This is at odds with recent events, as the euro weakened further against the dollar as equity prices fell. The discrepancy can be rationalized in two ways. First, the historical experience suggests a lag of about a year between equity price and exchange rate movements, in contrast to the model's prediction of a contemporaneous response. This may reflect recognition lags in markets, as discussed earlier. In this case, one might expect a delayed correction in the

${ }^{26}$ The magnitude of the rise depends on the elasticity of substitution between capital and labor in production and the intertemporal elasticity of substitution. With logarithmic utility and CobbDouglas production technology, as assumed here, the steady-state real interest ratc rises by the same amount as the increase in productivity growth.

${ }^{27}$ A two-sector framework that allowed for Balassa-Samuelson effects would be more likely to work in the right direction in terms of the exchange rate, but would encounter problems with other stylized facts, as discussed carlier. 
euro/dollar exchange rate in the foreseeable future. Alternatively, it could reflect other factors that are influencing the exchange rate. Among the possibilities, the next section discusses portfolio shifts in euro-denominated assets. A more general hypothesis is that markets have selectively chosen a set of fundamentals that rationalizes - and perpetuates - past dollar strength, along the lines of de Grauwe (2000). In this case, a turning point might only be realized when events decisively shift market sentiment.

Regarding the plausibility of the equity market story in terms of other major currencies, the yen has experienced massive gyrations in the 1990s that are not clearly related to equity prices. It seems plausible, however, that the Japanese economy has been hit by shocks, such as the problems in the financial sector and the Asian crisis, that have dominated those from equity markets. Studies also suggest that equity wealth has a limited direct impact on spending in Japan, thus one would not expect an important impact on the exchange rate. The U.K. case is perhaps more relevant. Equity market capitalization in the United Kingdom is similar to that in the United States, and rose by roughly as much relative to GDP

(Figure 8). It is interesting, then, that the U.K. experience in the late 1990s was very similar, with the exchange rate appreciating sharply in the face of strong, domestic-demand led growth, and the current account deteriorating at the same time.

\section{Portfolio Shifts}

As noted earlier, the introduction of the euro caused a surge of activity in regional financial markets (Galati and Tsatsaronis (2001)). One of the most prominent developments was a sharp rise in issuance of euro-denominated debt relative to that in predecessor currencies (Figure 20). This rise was broad-based, reflecting activity by both resident and nonresident issuers. Resident issuers appear to have substituted away from foreign-currency denominated instruments as the domestic capital market became much more liquid with the advent of a unified approach to assessing issues in the single currency. In addition, nonresident issuers appear to have been motivated by a desire to establish a presence in a new and important market. International investors, in contrast, have shown limited interest in euro-denominated debt, and most of the rise in issuance has been absorbed by domestic investors.

Detken and Hartmann (2000) focus specifically on the international component of the increase in euro-denominated debt, defined as issuance by non-residents of the euro area. Their conclusions for this segment of the market are similar to those above. They observe a significant rise in the share of euro-denominated securities in the market as a whole during 1999, which came at the expense of both the dollar and the yen; the increase is even more pronounced when adjustments are made to compensate for movements in currency values. Figure 21 presents updated data using these concepts through the first quarter of 2001. Growth in the share of euro-denominated debt rose further during 2000 and early 2001, bringing it to 27 percent on a constant-currency basis by the end of the period compared with a stable ratio of about 17 percent in the pre-euro period. They also find evidence that the 
Figure 20. New Issues of Euro-denominated Debt Securities

Percent of total issues in all currencies

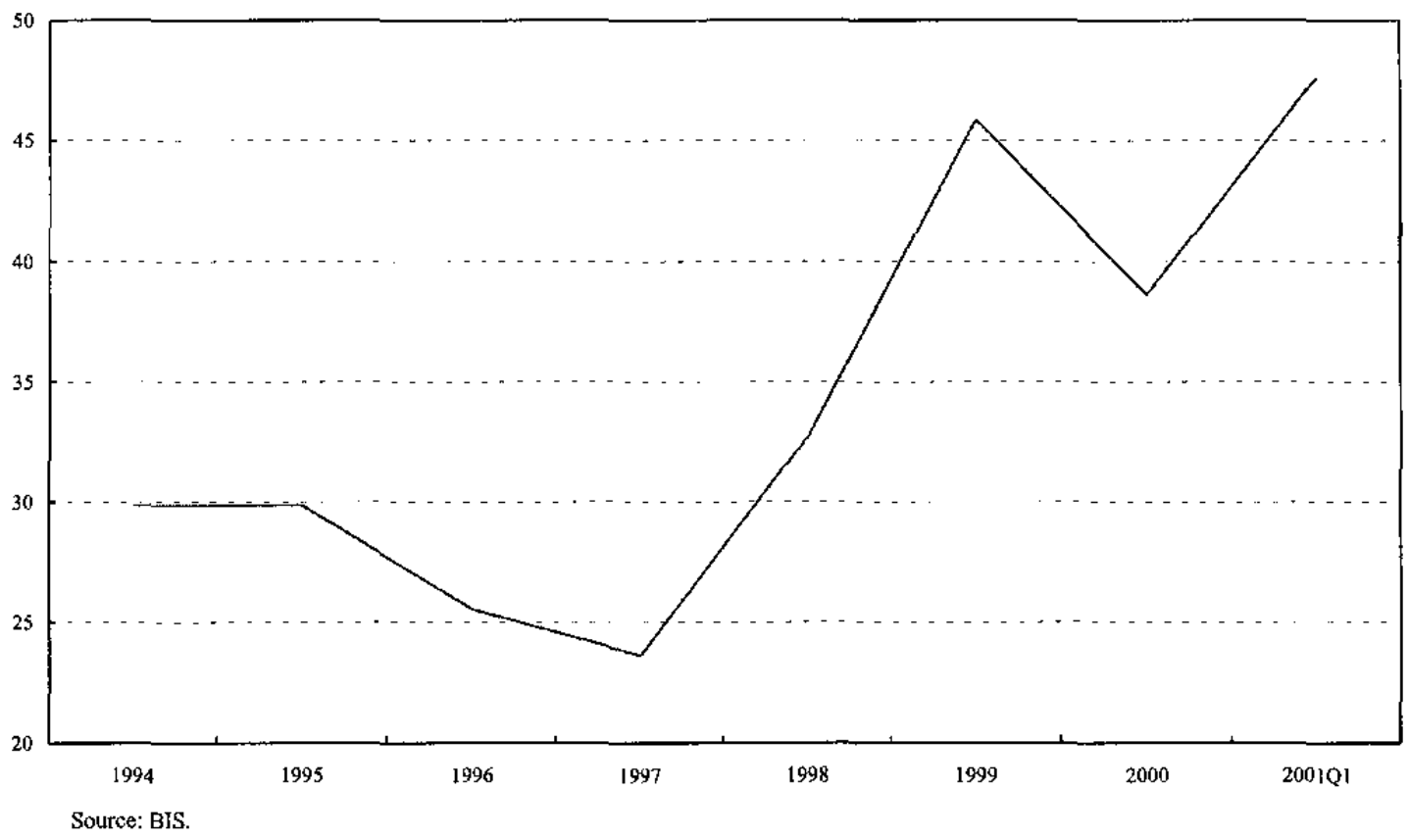

Figure 21. Euro-denominated Share of International Debt Issues

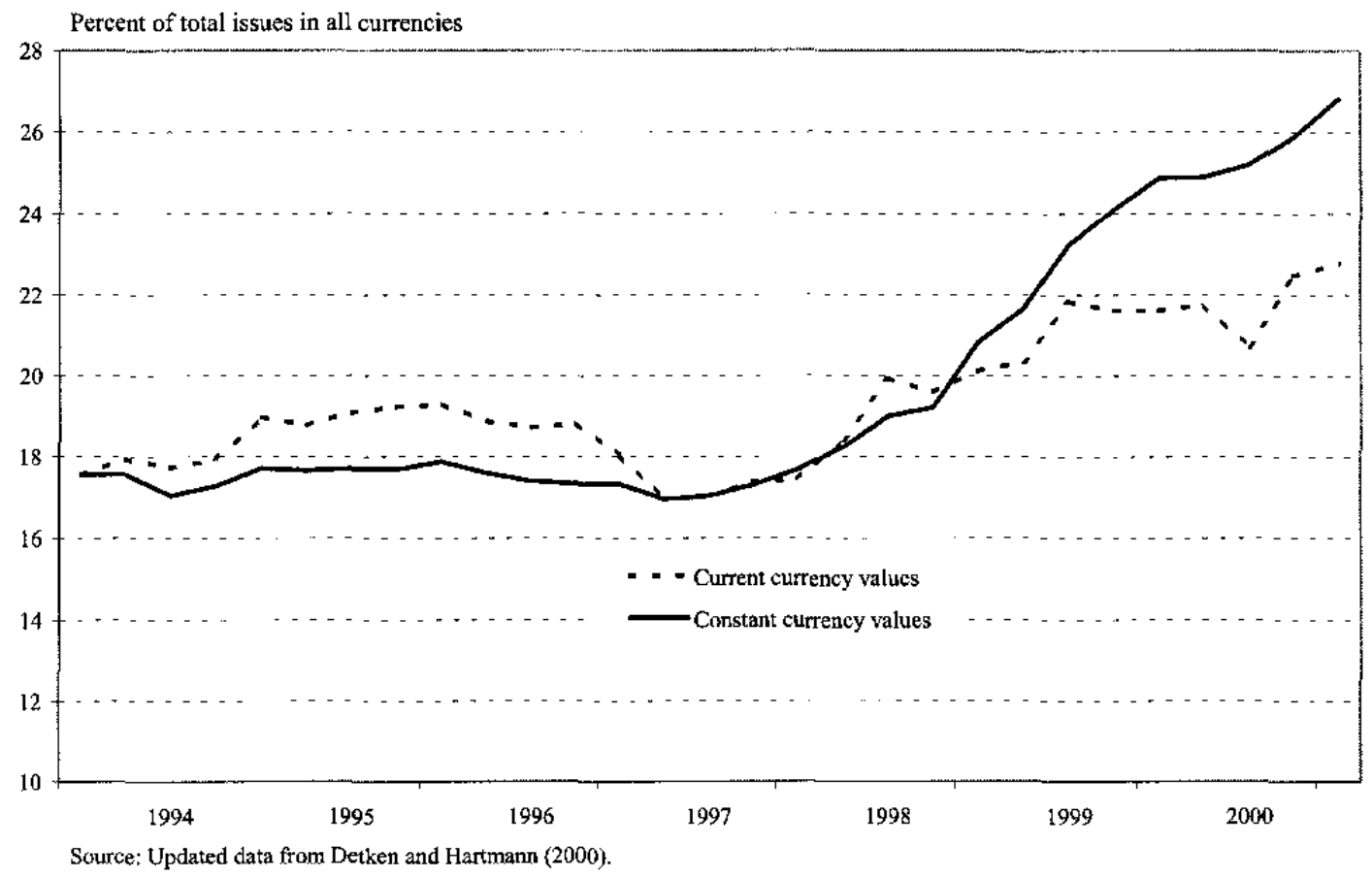


increased supply of euro bonds was primarily purchased by euro-area residents as opposed to outside investors.

Of course, the rise in euro-denominated debt issuance could have been caused either by an ex ante increase in the supply of debt by borrowers or in demand by investors. In the event, it appears that investor demand has not been the driving force. Firstly, there is the fact that little of the increased issuance was bought by international investors, in contrast to the activity on the borrowing side. For domestic investors, the market may have been made more attractive by the increased homogeneity and liquidity of euro-denominated issues.

Constraints on portfolio allocation, however, would have worked in the opposite direction. Limits are common on the share of non-domestic currencies in institutional portfolios to contain exposure to exchange-rate risk. ${ }^{28}$ While such risk would have declined among euroarea currencies prior to 1999 , this would not have relaxed portfolio constraints without explicit action to redefine exposure limits. The introduction of the euro as a domestic currency automatically relaxed these constraints. The purchase of German bonds by a French investor, for instance, would now count as an increase in domestic-currency as opposed to foreign-currency assets. Thus, this redefinition had the effect of "freeing up" assets for investment in foreign currencies.

Another factor that could have caused a shift out of euro-area currencies is the exchange of deutschemark banknotes for dollars by participants in underground activities in eastern Europe. The hypothesis is that they would not want to exchange deutsche marks for euros through conventional channels during the "hard" euro conversion in 2002. Sinn and Westermann (2001) provide evidence that deutschemarks circulating outside Germany have totaled about $€ 30$ billion, and suggest that a currency shift of this magnitude would represent a significant shock in exchange markets. While this may be true, it is dwarfed by the size of the capital market effects discussed above. For instance, the increase in the share of eurodenominated debt securities in constant currencies shown in Figure 21 from 1998 to the first quarter of 2001 implies a rise in euro-denominated debt of over $€ 300$ billion, or ten times the estimated value of deutsche mark cash held by nonresidents. Nevertheless, such a shift could have played a supporting role in depressing the euro.

The direction of these portfolio effects-toward increased borrowing and reduced investment in euros-would put downward pressure on the currency. ${ }^{29}$ Conceptually, the value of the euro would fall until its expected future appreciation offset the initial factors that induced the portfolio shifts. Over time, the exchange rate would return back toward its original level, while the effects of the portfolio shift would be reflected in prices, asset stocks, and interest rates. A full treatment of these issues would require the specification and

${ }^{28}$ An example is French and Belgian pension funds, which are required by law to maintain at least 80 percent of their portfolio in domestic-currency assets.

${ }^{29}$ McCauley (1997) has one of the first discussions of this effect. 
estimation of a portfolio balance model for global investment flows. Building sych models, though, is notoriously difficult given data limitations, simultaneity problems, and structural shifts. All of these issues would be relevant in the context of modeling the introduction of the euro. Instead, we adopt an indirect approach. This is to assume a shock to the "excess yield" on euro assets in the model used in Section $V$ that would proxy for the portfolio effects of introducing the euro. While only illustrative, this exercise gives a feel for the magnitude and dynamics of the exchange rate change that would accompany such a shock.

The shock itself was assumed to be 20 basis points on the excess yield on ROW assets in 1999 and another 20 basis points in 2000 for a cumulative rise of 40 basis points. ${ }^{30}$ This can be thought of a combination of the higher direct costs borrowers would pay to offset the advantages of issuing in euros, and the higher yield necessary to induce lenders to remain in euro assets. The size of the shock is somewhat arbitrary in the absence of an appropriate theoretical metric, and the results are presented as an illustration of the possible size of the effect. In the event, the effect is significant, leading to a depreciation of the euro of 17 percent by 2000 (Figure 22). Over the long run, the exchange rate would gradually adjust back toward its initial level, while the interest differential between the two regions would widen to reflect the shock to equilibrium yields (Figure 23). The combination of the shock from equity markets described earlier and this hypothetical portfolio effect would account for a total shift in the euro/dollar of about 40 percent by 2000 , similar to the actual experience.

\section{Concluding Remarks}

Many hypotheses have been advanced for why the euro has weakened in recent years. Some appear implausible on conceptual grounds, while others have encountered problems with the evidence as time has passed. In any case, it seems unlikely that any single cause can explain recent exchange rate movements among the major currencies, as they appear to reflect phenomena specific to both the U.S. and euro-area economies.

This paper identifies two factors that are theoretically consistent with observed exchange rate movements, and also the broad macroeconomic effects that have accompanied them. The first is the surge in global equity values since the mid-1990s, which resulted in a shock that disproportionately affected the U.S. economy. Not only the rise in the dollar against most other currencies, but many other aspects of the "new economy," are consistent with this shock. The second is the shift in portfolio behavior that accompanied the introduction of the euro. Available evidence points to a surge in issuance of euro debt by borrowers, and a shift toward non-euro assets by lenders. While the effects are hard to

${ }^{30}$ For this shock the relative size of the two areas was reversed so that the ROW, now interpreted as the euro area, accounted for $1 / 3$ of total output. The shock was implemented by introducing a constant $\varepsilon$ into the uncovered interest parity condition for the exchange rate (equation (1) in the text or (A.30) in Annex A). 
Figure 22. Simulated Euro Exchange Rate: Shock to Excess Yield

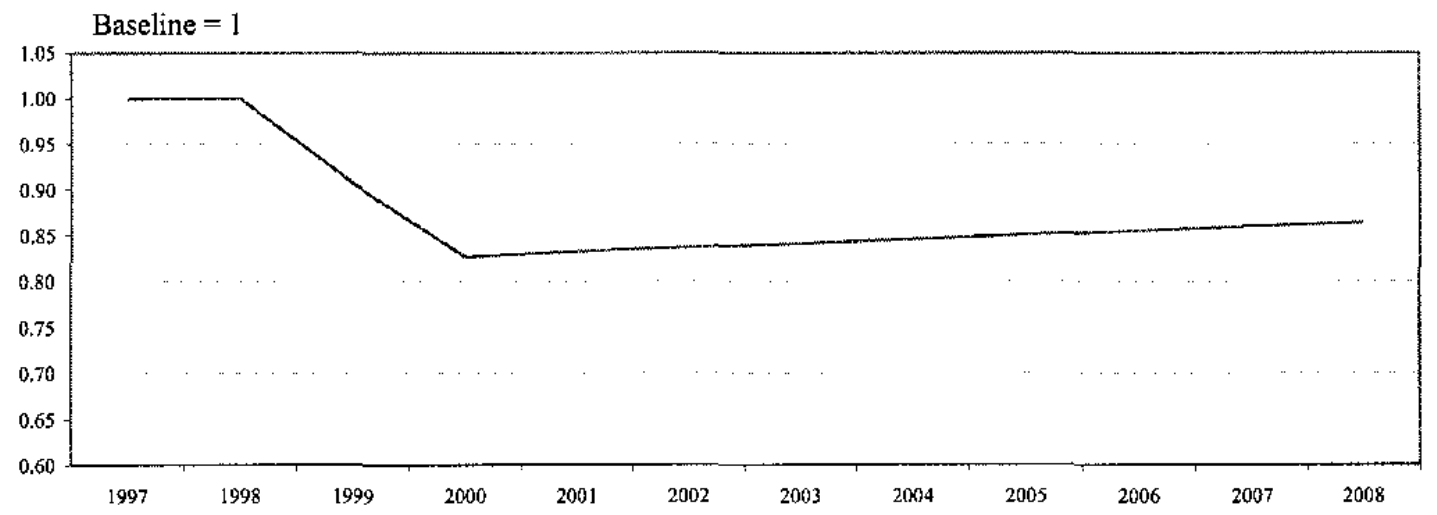

Source: Staff calculations.

Figure 23. Simulated Real Interest Rates: Shock to Euro Excess Yield

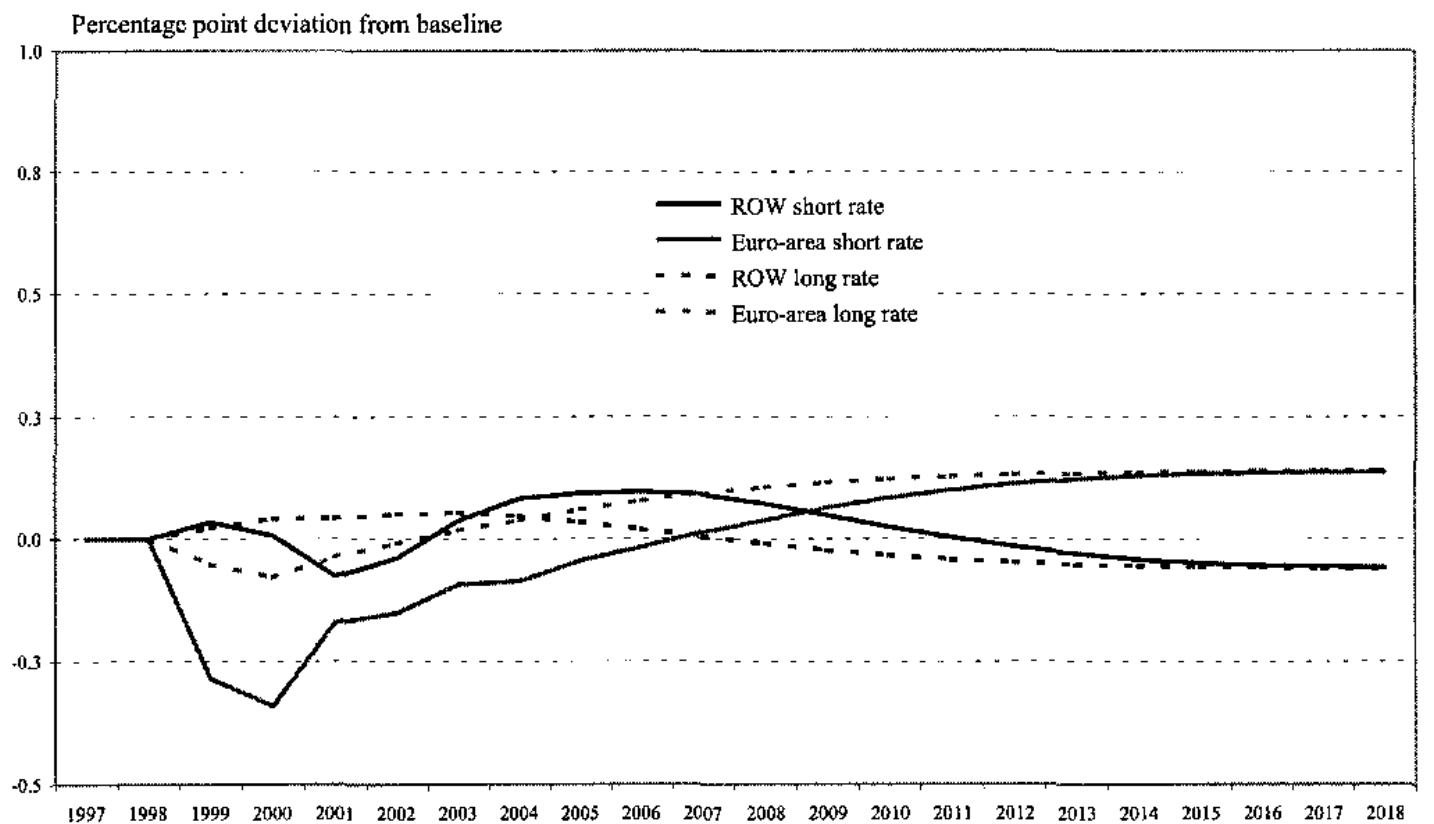

Source: Staff calculations. 
quantify precisely, illustrative simulations suggest that they can plausibly explain the component of euro weakness that coincided with its introduction.

Looking ahead, these factors are unlikely to intensify. Indeed, the (partial) correction in equity prices since peaks in 2000 should work in the opposite direction, creating scope for some reversal of the euro weakness. Similarly, the portfolio effects associated with the introduction of the euro are likely to have be strongest in the early stages, when the latent gap between supply and demand for euro assets was largest. As portfolio allocations adjust over time, and international interest rate differentials shift to accommodate the shift in asset demands, the exchange rate effects should diminish.

As far as economic policies are concerned, the explanations advanced here for euro weakness do not suggest a direct role for policies as a corrective tool. Clearly, though, the weak euro has had implications for activity and prices in the euro area, and these have influenced policy formulation. If, indeed, the fundamental forces that have driven down the euro are beginning to unwind, an important factor behind the shocks to euro-area inflation would reverse, allowing scope for greater monetary easing.

At the same time, the importance of speculative market forces should not be downplayed, especially against the background of large, unexpected currency movements. Historical experience, for instance with the yen in 1995 and 1998, suggests that market uncertainty about fundamentals is magnified by past volatility. In addition, there is the question of the factors driving equity price movements. It remains open to question how much of the run-up in equity prices has been driven by a shift in equilibrium yields on equities versus "irrational exuberance" about future earnings growth. If market expectations have become distorted, equity prices could be vulnerable to a much larger adjustment that yet observed, with consequent implications for exchange rates. 


\section{REFERENCES}

Bailey, A, S. Millard, and S. Wells (2001), "Capital flows and exchange rates," Bank of England Quarterly Bulletin, Autumn, pp. 310-318.

Bryant, R, P. Hooper and C. Mann (1993), Evaluating Policy Regimes, The Brookings Institution (Washington).

Corsetti, G. and P. Pesenti (1999), "Stability, Asymmetry, and Discontinuity: The Launch of the European Monetary Union," in Brookings Papers on Economic Activity, Vol. 2, pp. 295-358.

DeBroeck, M. and T. Sløk (2001), IMF Working Paper WP/01/56, May.

De Grauwe, Paul (2000), "The Euro-Dollar Exchange Rate in Search of Fundamentals," unpublished manuscript, June.

Detken, Carsten and Philipp Hartmann (2000), "The Euro and International Capital Markets," European Central Bank Working Paper No. 19, April.

Edison, Hali and Torsten Sløk (2001a), "Wealth Effects and the New Economy," IMF Working Paper WP/01/77, June.

Edison, Hali and Torsten Sløk (2001b), "New Economy Stock Valuations and Investment in the 1990s," IMF Working Paper WP/01/78, June.

Epaulard, Anne and Aude Pommeret (2001), "Agents' Preferences, the Equity Premium, and the Consumption-Saving Trade-Off: An Application to French Data," IMF Working Paper WP/01/117, August.

Galati, G. and K. Tsatsaronis (2001), "The impact of the euro on Europe's financial markets," BIS Working Paper No. 100, July.

Hunt, B., P. Isard and D. Laxton (2001), "The Macroeconomic Effects of Higher World Oil Prices," IMF Working Paper WP/01/14, January.

IMF (1998), Exchange Rate Assessment: Extensions of the Macroeconomic Balance Approach, IMF Occasional Paper 167, P. Isard and H. Faruqee (eds.)

IMF (2001), World Economic Outlook, Chapter II, May.

Koen, V., L. Boone, A. de Serres, and N. Fuchs (2001), "Tracking the Euro," OECD Economics Department Working Paper No. 298, June. 
McCauley, R. (1997), "The euro and the dollar," Essays in International Finance, No. 205, Princeton.

Mehra, R. and E.C. Prescott (1985), "The equity premium: a puzzle," Journal of Monetary Economics, Vo. 15, March, pp. 145-61.

Meredith, G. (1998), "The Yen: Past Movements and Future Prospects," in Structural Change in Japan, B. Aghevli, T. Bayoumi, and G. Meredith eds, IMF.

Meredith, G. (2001), "Uncovered Interest Parity and the Monetary Transmission Process," in Transmission Channels of Monetary Policy, P. Sinclair and L. Mahadeva eds., Bank of England Centre for Central Banking Studies, forthcoming

Nordhaus, W.D. (2001), "Productivity Growth and the New Economy," NBER Working Paper 8096, January.

OECD (2001), OECD Economic Surveys 2000-2001: Euro Area, May 2001.

Owen, David (2001), "Importance of Productivity Trends for the Euro," in European Economics for Investors, Dresdner Kleinwort Wasserstein, March 21.

Schinasi, Garry, Charles Kramer, and R. Todd Smith (2001), "Financial Implications of the Shrinking Supply of U.S. Treasury Securities," IMF Working Paper WP/01/61, May.

Shiller, Robert J. (2000), Irrational Exuberance, Princeton University Press (Princeton).

Siegel, Jeremy J. (1994), Stocks for the Long Run, McGraw-Hill (New York).

Sinn, Hans-Werner and Frank Westermann (2001), "Why Has the Euro Been Falling? An Investigation into the Determinants of the Exchange Rate," NBER Working Paper 8352 , July.

Staiger, D., J. Stock, and M. Watson (2001), "Prices, Wages, and the U.S. NAIRU in the 1990s," NBER Working Paper 8320, July.

Summers, L.H. (1981), "Taxation and Investment: A q-Theory Approach,” Brookings Papers on Economic Activity, Vol. 1, pp. 67-140.

Tille, C., N. Stoffels, and O. Gorbachev (2001), "To What Extent Does Productivity Drive the Dollar?," Federal Reserve Bank of New York Current Issues in Economics and Finance, Vol. 7, No. 8, August, pp. 1-6. 


\section{DESCRIPTION OF MODEL}

The model is a calibrated annual model similar to the IMF's MULTIMOD. It consists of two regions, the U.S. and the rest of the world (ROW), with the U.S. representing one third of overall output and the ROW two thirds. The structure of the two blocks is generally identical, with a few exceptions described below. Financial markets are forward looking, and there is complete capital mobility between the two regions.

The baseline data are artificial, with both regions initially on equilibrium growth paths. There are no residuals in the equations, which hold exactly. Conceptually, there are two notable differences relative to MULTIMOD. The first involves price determination: unlike MULTIMOD, there is an explicit labor market that determines employment and wages; aggregate prices are then a function of wages, imported costs, and profit margins. The second is in the structure of business financing. While all financing in MULTIMOD is assumed to be in the form of equities, this model incorporates both debt and equity financing. This allows a distinction between the two regions in terms of the baseline share of equity in total business financing, and thus the effect of an equity price shock on wealth and spending.

The model structure is summarized below; mnemonics and variable descriptions are provided in Table A.1.

\section{Consumption and Wealth}

Consumption is based on the Blanchard-Yaari framework, with an allowance for consumers that are temporarily liquidity-constrained. Total wealth consists of human wealth plus asset wealth. Both are determined by forward-looking assessments of the discounted value of future income streams to labor and capital.

$$
\begin{gathered}
C=\gamma W *\left(Y D / Y D_{-1}\right)^{0.5} \\
\gamma=(1+r *(1-\sigma)+c 0) *\left(\gamma_{+1} /\left(1+\gamma_{+1}\right) .\right. \\
Y D=(1-\alpha) *(Y *(P / P C)-T) \\
W=W H+W K+N F A+G B \\
W H=\left(Y D+W H_{+1}\right) /(1+r+v)
\end{gathered}
$$

The propensity to consume out of wealth, $\gamma$, is calibrated by varying the excess discount rate on human wealth, $v$, which in turn affects the ratio of wealth to consumption. Values for $v$ of 0.052 for the U.S. and 0.025 for the ROW yield values for $\rho$ of 0.05 and 0.03 respectively. These propensities to consume out of wealth are consistent with typical 
estimates of wealth effects on consumption. ${ }^{31}$ The response of consumption to interest rates is determined by the intertemporal elasticity of substitution, $\sigma$. For the simulations presented in the text, $\sigma$ was set to unity -a higher (i.e. more "elastic") value than is often estimated from aggregate time-series data. This value was selected to yield plausible global interest rate effects from the equity market shocks. In particular, lower elasticities of substitution generated very large increases in real interest rates, while the actual experience indicates that global real interest rates rose only moderately, if at all, in the late 1990s. It is difficult to reconcile the size of the demand shock that is consistent with standard consumption and investment relationships and the observed behavior of real interest rates without assuming that consumption is relatively interest-elastic. Clearly this is an area where further research is needed to reconcile different estimates of the intertemporal elasticity of substitution.

\section{Investment}

Business investment is determined by a Tobin's $q$ relationship. The main difference from MULTIMOD is that this model embodies both debt and equity financing. Reflecting this difference, business profits per share outstanding are defined to be net, not only of depreciation, but also debt-servicing costs. The price of a share is then equal to the discounted value of per-share profits, where the discount rate equals the sum of the real interest rate and the "equity premium"-i.e. the expected excess return on equities relative to the government bond yield. The baseline value of the premium is set at $51 / 4$ percentage points, consistent with the historical excess return on U.S. equities through the mid-1990s. The speed of adjustment of the capital stock to $q$ is calibrated to be consistent with the estimates of equity valuations on investment discussed in Edison and Sløk (2001b). The proportion of the capital stock that is financed by equity versus debt differs in the baseline between the two regions, as discussed in the text. In the simulations, the ratio of debt to GDP is held constant, and new capital formation is financed by equities, consistent with the experience in the late 1990s.

$$
\begin{gathered}
\pi=\left\{\alpha(Y *(P / P C)-T)-\delta K_{-1}-r^{b} B D_{-1}\right\} / S \\
P Q=\left(\pi+P Q_{+1}\right) /(1+r+\rho) \\
S=K-B D \\
W K=P Q * S+B D \\
\Delta \ell n(K)=0.05 * \ln \left(W K_{-1} / K_{-1}\right)+\Delta \ln \left(Y^{P}\right)
\end{gathered}
$$

${ }^{31}$ See Edison and Sløk (2001a) for a discussion of recent estimates. For North America and the UK, they estimate an average MPC of 0.052 out of equity wealth in traditional stocks, and 0.040 out of "ncw economy" stocks. 


\section{Table A.1: Model Mnemonics and Variable Definitions}

Mnemonic

\begin{tabular}{|c|c|}
\hline$Y$ & real output \\
\hline$Y^{P}$ & potential rcal output \\
\hline$D D$ & real domestic demand \\
\hline$C$ & real consumption \\
\hline$I N V$ & real business investment \\
\hline$W$ & total real wealth \\
\hline$Y D$ & real labor income \\
\hline$\gamma$ & ratio of consumption to wealth \\
\hline$r$ & real short-term interest rate \\
\hline$r^{s s}$ & steady-state $r$ \\
\hline$r^{b}$ & real interest rate on business debt \\
\hline$\sigma$ & intertemporal elasticity of substitution \\
\hline$P$ & output deflator \\
\hline$P C$ & absorption deflator \\
\hline$P Q$ & real equity price \\
\hline$G$ & real government spending \\
\hline$T$ & real taxes \\
\hline$\tau$ & tax rate \\
\hline$G B$ & real net government debt \\
\hline$W H$ & real human wealth \\
\hline$W K$ & real market value of capital stock \\
\hline$K$ & real capital stock \\
\hline$S$ & number of shares outstanding \\
\hline$B D$ & business sector debt \\
\hline$\pi$ & business profit per share \\
\hline$\alpha$ & capital share in output \\
\hline$\rho$ & risk premium on capital \\
\hline$\delta$ & depreciation rate on capital \\
\hline$v$ & excess discount rate on future labor income \\
\hline$L$ & actual labor input \\
\hline$L^{P}$ & potential labor input \\
\hline$W$ & wage \\
\hline$W R^{e}$ & expected "warranted" rcal wage \\
\hline$I M$ & real imports \\
\hline$E X$ & real exports \\
\hline$P M$ & import price \\
\hline$P X$ & export price \\
\hline$T B$ & real trade balance \\
\hline$N F A$ & real net foreign assets \\
\hline$E R$ & nominal exchange rate (price of foreign currency) \\
\hline$R E R$ & real exchange rate (output price deflated) \\
\hline
\end{tabular}

\section{Baseline value}

$3 \%$ annual growth

$Y$
$Y$
$0.65^{*} Y$
$0.15^{*} Y$
$12.8^{*} Y$
$0.58^{*} Y$
0.05
0.03
0.03
0.06
1.0

1
1
1

$0.20 * Y$
$0.20 * Y$
0.20
0

$11.2 * Y$
$1.6 * Y$
$1.6 * Y$
$0.5 * K$
$0.5 * K$
0.083
0.27
0.052
0.065
0.052

$1 \%$ annual growth $L$ $2 \%$ annual growth $W$

$0.12 * Y$
$0.12 * Y$
1
1
0
0
1
1




\section{Government Sector}

The ratio of government spending to potential output is exogenous; the tax rate then adjusts according to a reaction function that ensures a bounded ratio of government debt to GDP. Baseline shares of spending and taxes in GDP are 20 percent.

$$
\begin{gathered}
G * P C=0.20 * Y^{P} * P \\
T=\tau(Y * P) \\
\Delta \tau=0.30 * \Delta\left\{\left(G B_{-1} * P C_{-1}\right) /\left(Y_{-1}^{P} * P_{-1}\right)\right\}+0.05 *\left\{\left(G B_{-1} * P C_{-1}\right) /\left(Y_{-1}^{P} * P_{-1}\right)\right\} \\
G B=(1+r) * G B_{-1}+G-T
\end{gathered}
$$

Trade Flows and Prices

Imports are determined by a conventional demand relationship that is a function of domestic spending and relative prices. The spending elasticity is 1.5 in the short run and 1 in the long run. The relative price is defined as the import price divided by the domestic output deflator. Import prices are determined by the export prices of the other region. In the short run, exporters (partially) price to market, setting prices as the average of domestic output prices and the output price of the other region. In the long run, competition among exporters drives the export price to the home output price. The price elasticity of import demand is -0.3 in the short-run and -1 in the long run. Exports of each region are simply the imports of the other region, ensuring global adding-up of trade flows. The baseline shares of imports and exports in GDP are set to 12 percent for the U.S., similar to the shares of goods and services trade in national accounts data. Net foreign assets are the cumulated value of trade balances plus net investment income, where the latter is the lagged level of NFA times the interest rate.

$$
\begin{gathered}
\Delta \ell n(I M)=\Delta \ell n\left(Y^{p}\right)+1.5 * \Delta \ell n\left(D D / Y^{P}\right)+0.3 * \ln \left\{0.12 *(P / P M) *\left(D D / I M_{-1}\right)\right\} \\
E X=I M^{f} \\
T B=(E X * P X-I M * P M) / P C \\
N F A=(1+r) * N F A_{-1}+T B \\
\Delta \ell n(P X / P)=0.5 * \Delta \ell n\left\{\left(P^{F} / E R\right) / P\right\}+0.5 * \ln \left(P_{-1} / P X_{-1}\right) \\
P M=P X^{r} / E R
\end{gathered}
$$

\section{Actual and Potential Output}

Potential output is determined by a Cobb-Douglas production function. The capital input is the observed value of the capital stock, while the labor input is the "potential" level of the labor force abstracting from cyclical considerations. Productivity is equal to an 
exogenous underlying trend. With productivity growth of $2 \%$ per year and labor force growth of $1 \%$, potential output grows by $3 \%$ per year in the long run. Actual output is demand determined, with both productivity and the actual labor input varying in the short run such that the productive inputs are consistent with aggregate demand for output. The cyclical sensitivity of the labor input is determined by an Okun's Law type relationship, such that a 1 percent change in the cyclical component of output is associated with an 0.4 percentage point change in employment. Productivity is the residual factor.

$$
\begin{gathered}
Y^{p}=K^{\alpha} *\left(\bar{\mu} L^{P}\right)^{(1-\alpha)} \\
Y=K^{\alpha} *(\mu L)^{(1-\alpha)} \\
L / L^{P}=\left(Y / Y^{P}\right)^{0.4}
\end{gathered}
$$

Wages and Prices

Nominal wage growth is determined by three factors: expected inflation; the unemployment rate; and expectations of "warranted" real wage growth. Warranted real wage growth is the growth rate of real wages that would be consistent with maintaining full employment. Thus it equals underlying growth in labor productivity, which in turn reflects trends in both underlying productivity and the equilibrium capital-output ratio. Underlying productivity growth is exogenous, while the equilibrium capital-output ratio is a function, inter alia, of the discount rate applied to future profits, including the equity premium.

Wage setters in the model look backwards in assessing growth in warranted real wages by taking a four-year moving average of past observed real wage growth. The motivation is that it is difficult to assess warranted real-wage growth in a forward-looking manner given the complexity of its determination, and the difficulties in distinguishing between temporary and underlying factors in current data. The response of wage growth to the unemployment rate is such that a 1 percentage point rise in the unemployment rate is assumed to reduce wage growth by 0.5 percentage points per year. ${ }^{32}$

$$
\begin{gathered}
\Delta \ell n W=(1 / 2) * \ln \left(P C / P C_{-2}\right)+\Delta \ell n W R^{e}+0.5 * \ln \left(L / L^{P}\right) \\
\Delta \ell n W R^{e}=(1 / 4) *\left\{\Delta \ln \left(W_{-1} / W_{-5}\right)-\Delta \ln \left(P C_{-1} / P C_{-5}\right)\right\}
\end{gathered}
$$

The price of domestic output is determined as a mark up over normalized unit labor costs, with the mark-up margin depending on the ratio of actual to potential output. Consumer prices are based on a weighted average of the domestic output price and imported prices, with the weights reflecting the share of imports in GDP.

$$
P=\{1 /(1-\alpha)\} *\left(W * L^{P} / Y^{P}\right) *\left(Y / Y^{P}\right)^{a}
$$

${ }^{32}$ This value is similar to that recently estimated for the U.S. by Staiger and others (2001). 


$$
P C=P^{(1-i m 0)} * P M^{i m 0}
$$

Interest Rates and the Exchange Rate

Short-term interest rates in both regions are set according to conventional Taylor Rules using the original parameters. The equilibrium real interest rate, embodied in the constant term, is allowed to change over time, based on a backward-looking four-year moving average of the observed real interest rate-the same approach as used for warranted real wage growth. There is no need for a long-term real interest rate in the model; rather, present-value calculations are based on the expected future path of the short-term real rate.

$$
\begin{gathered}
r=r^{s s}+0.5 *\left\{\Delta \ln (P)+\ln \left(Y / Y^{P}\right)\right\} \\
r^{s s}=(1 / 4) *\left(r_{-1}+r_{-2}+r_{-3}+r_{-4}\right)
\end{gathered}
$$

The expected change in the real exchange rate is determined by uncovered interest parity, consistent with the assumption of perfect capital mobility. The current level of the exchange rate then reflects the future path of interest rates, as well as expectations of the long-term equilibrium level of the exchange rate. The nominal exchange rate is defined residually from the real exchange rate and the relative price level.

$$
\begin{gathered}
\ell n R E R_{+1}^{e}-\ell n R E R=\ln \left\{\left(1+r^{f}\right) /(1+r)\right\} \\
E R=R E R *\left(P^{f} / P\right)
\end{gathered}
$$



